\title{
On the factors influencing surface-layer energy closure and their seasonal variability over the semi-arid Loess Plateau of Northwest China
}

\author{
X. Xiao ${ }^{1,2}$, H. C. Zuo ${ }^{1}$, Q. D. Yang ${ }^{1}$, S. J. Wang ${ }^{1}$, L. J. Wang ${ }^{1}$, J. W. Chen ${ }^{1}$, B. L. Chen ${ }^{1}$, and B. D. Zhang ${ }^{1}$ \\ ${ }^{1}$ Key Laboratory for Semi-Arid Climate Change of the Ministry of Education, College of Atmospheric Sciences, \\ Lanzhou University, Lanzhou, Gansu, China \\ ${ }^{2}$ State Key Laboratory of Numerical Modeling for Atmospheric Sciences and Geophysical Fluid Dynamics, \\ Institute of Atmospheric Physics, Chinese Academy of Sciences, Beijing, China \\ Correspondence to: H. C. Zuo (zuohch@lzu.edu.cn)
}

Received: 5 December 2010 - Published in Hydrol. Earth Syst. Sci. Discuss.: 19 January 2011

Revised: 8 February 2012 - Accepted: 12 February 2012 - Published: 20 March 2012

\begin{abstract}
The energy observed in the surface layer, when using eddy-covariance techniques to measure turbulent fluxes, is not balanced. Important progress has been made in recent years in identifying potential reasons for this lack of closure in the energy balance, but the problem is not yet resolved. In this paper, long-term data that include output of tower, radiation, surface turbulence flux and soil measurement collected from September 2006 to August 2010 in the Semi-Arid Climate Change and Environment Observatory, Lanzhou University, in the semi-arid Loess Plateau of Northwest China, were analysed, focusing on the seasonal characteristics of the surface energy and the factors that have impact on the energy balance closure (EBC). The analysis shows that (1) the longterm observations are successful; the interaction between the land and the atmosphere in semi-arid climates can be represented by the turbulent transport of energy. In addition, even though the residual is obvious, this suggests that the factors that impact the EBC are stable, and their seasonal variations are identical. The analysis also shows that (2) four factors have obvious impact on the EBC: the diverse schemes for surface soil heat flux, the flux contribution from the target source area, the low-frequency part of the turbulence spectra, and the strength of atmospheric turbulence motion. The impact of these four factors on the EBC are similar in all seasons. Lastly, the results indicate that (3) atmospheric turbulence intensity is a very important factor in terms of its impact on the EBC. The relative turbulence intensity, $\mathrm{RI}_{w}$, characterises the strength of atmospheric turbulence motion, and is found to exert a noticeable impact on the EBC; in all seasons, the EBC is increased when the relative turbulence intensity is enlarged.
\end{abstract}

\section{Introduction}

Exchange processes of energy, water, and carbon at the bottom of the atmospheric boundary layer, the dominant aspect of interaction between the atmosphere and land, are crucial for the soil-plant-atmosphere system. Their exchange properties exert a significant impact on atmospheric motion and surface environmental conditions, and are related to weather, climate, ecosystems, and the hydrologic cycle (Running et al., 1999; Canadell et al., 2000; Betts et al., 1996; Pielke et al., 1998). The eddy-covariance (EC) technique is the most direct method for quantifying the turbulent exchange of energy between the Earth's surface and the atmosphere. Measurements of these processes can improve our understanding of the global climate system. For example, such measurements proved the Monin-Obukhov (M-O) similarity and made the M-O similarity useful since the 1970s. The EC technique has become a standard tool in the study of the terrestrial carbon, water, and energy cycles (Sellers et al., 1996; Baldocchi et al., 2001). Energy balance closure (EBC), a formulation of the first law of thermodynamics, requires that the sum of the directly measured latent and sensible heat flux be equivalent to all other energy sinks and sources, which is observed without exception in all numerical simulations that make use of the exchange flow of energy and water. However, during the late 1980s, it became apparent that the energy balance at the Earth's surface could not be closed with experimental data (McCaughey, 1985; Foken and Oncley, 1995). Since then, the EBC has become an exceedingly prominent problem in studies of atmosphere-land interaction. Panin et al. (1998) indicated that the energy balance 
unclosure bears a relation to the complicated underlying surface, i.e. heterogeneous land surface will affect the EBC. McCaughey (1985) analysed the effects of heat storage in the canopy at different heights on EBC. Wilson et al. (2002) noted that the heat storage term is greatly underestimated for morning EBC based on data from several FLUXNET sites. Finnigan et al. (2003) analysed the influence of an insufficient averaging interval of turbulent flux on the energy closure problem; a heterogeneous surface would generate eddies whose time-scale is too large for the eddy-covariance method to measure, implying that the low-frequency component of the turbulence spectra would have different-degree influence on EBC. In turn, Moncrieff et al. (2005) and Foken et al. (2006) used Ogive-analysis to study this low-frequency contribution to the turbulent energy exchange. Rebmann et al. (2005) discussed the flux source-area analysis contribution to turbulent energy exchange. In their Energy Balance Experiment (EBEX), Oncley et al. (2007) made a detailed study of the effect on EBC of the principal components of surface energy equilibrium, arriving at the conclusion that the advection between canopy top and flux measuring height is likely to have an impact upon EBC. Göckede et al. (2008) recommended that a footprint filter be included as additional information in the CarboEurope-IP database in order to indicate the representation level of each stored flux measurement. Half of the sites analysed by Göckede et al. (2008) experienced a significant reduction in EC data quality under certain conditions. Therefore, the contribution of the measured eddy-covariance flux from the target area directly affects the EBC, and the influence of land surface heterogeneity on EBC can be understood by analysing the difference of the flux contribution. Foken (2008) gave an overview of the existing researches on $\mathrm{EBC}$; it shows that this problem is a scale problem: large scales of the heterogeneous landscape have a significant influence on EBC. Hendricks Franssen et al. (2010) also reported a large multi-site analysis on EBC. In general, the causes of EBC as concluded from the aforementioned studies can be summarised as follows: (i) equipment limitations, such as systematic bias and mismatch in source areas for the terms in the energy balance equation; (ii) inaccurate estimation of energy fluxes and omission of energy sinks; and (iii) loss of low and/or high frequency contributions to turbulent fluxes.

Even with considering the above factors, it is difficult to fulfill complete EBC. Therefore, we must take into account not only the observation techniques and the calculation methods, but also the turbulence itself, i.e. the state of atmospheric motion. Furthermore, the investigation of EBC focuses on different sites ( $\mathrm{Li}$ et al., 2005; Wilson et al., 2002), lacking any systematic analysis of their seasonal characteristics (Wilson et al., 2002). Thus, it is imperative to improve our understanding of this problem as well as to determine possible causes. This is particularly relevant in the Loess Plateau of China, since it ranges from the Taihang Mountain in the east to the Riyue Mountain in the west $\left(114-101^{\circ} \mathrm{E}\right)$, and from the Qinling Range in the north to the Great Wall in the south $\left(34-40^{\circ} \mathrm{N}\right)$, with an area over $400000 \mathrm{~km}^{2}$. In 2006, the Semi-Arid Climate Change and Environment Observatory, Lanzhou University (SACOL) was set up in Yuzhong, Gansu, which also belongs to the semi-arid region of the Loess Plateau in the northwest semi-arid region of China. SACOL was a also part of CEOP (Coordinated Energy and Water Cycle Observations Project) for approximately $5 \mathrm{yr}$.

This study makes a thorough examination of long-term EBC features using the SACOL eddy-covariance dataset obtained from September 2006 to August 2010. In particular, we focus on the state of atmospheric motion and seasonal characteristics, in hopes of contributing to the existing literature on the EBC problem.

\section{Observation site, data quality control, and calculating methods}

\subsection{Observation site}

The SACOL observation site is situated at Mt. Tsui Ying at an elevation of $1965.8 \mathrm{~m}$ at $35^{\circ} 57^{\prime} 46^{\prime \prime} \mathrm{N}, 104^{\circ} 8^{\prime} 13^{\prime \prime} \mathrm{E}, 48 \mathrm{~km}$ from the centre of Lanzhou city, and covers an area of 8 ha. The topography around the site is characterised by the Loess Plateau, consisting of plains, ridges, and mounds. The terrain where the measurements were carried out is flat and covered with short grass. The densest vegetation coverage is in autumn, and the average vegetation height is only $0.3 \mathrm{~m}$. Figure 1a shows the typical landscape around the site, and Fig. $1 \mathrm{~b}$ shows the vegetation at SACOL's location and some of the equipment installed. The prevalent (sub-prevalent) wind direction is southwest (northeast) throughout the year at the summit, and the average annual wind speed is about $1.6 \mathrm{~m} \mathrm{~s}^{-1}$. The average annual temperature at the summit is $6.7^{\circ} \mathrm{C}$, and seasonally, the temperature ranges from an average temperature of $-8^{\circ} \mathrm{C}$ in January and $19^{\circ} \mathrm{C}$ in July. The summit get an average annual rainfall of $381.8 \mathrm{~mm}$, and average annual relative humidity is $63 \%$. In addition, annual sunshine hours are approximately $2600 \mathrm{~h}$. The site and its surroundings support little or no human activity, so it represents a primary regime of landform and vegetation in an arid and semi-arid climate of the Loess Plateau (Huang et al., 2008).

SACOL consists of a large set of instruments and measuring devices, as follows:

1. Boundary layer meteorological tower. This measures wind speed, air temperature, and relative humidity at 1 , $2,4,8,12,16$, and $32 \mathrm{~m}$. Wind direction is also measured at $8 \mathrm{~m}$. Signals are logged to a Campbell CR23X data logger and recorded at half-hour intervals.

2. Surface radiation monitoring system. This consists of upward and downward pyranometers for incoming and 

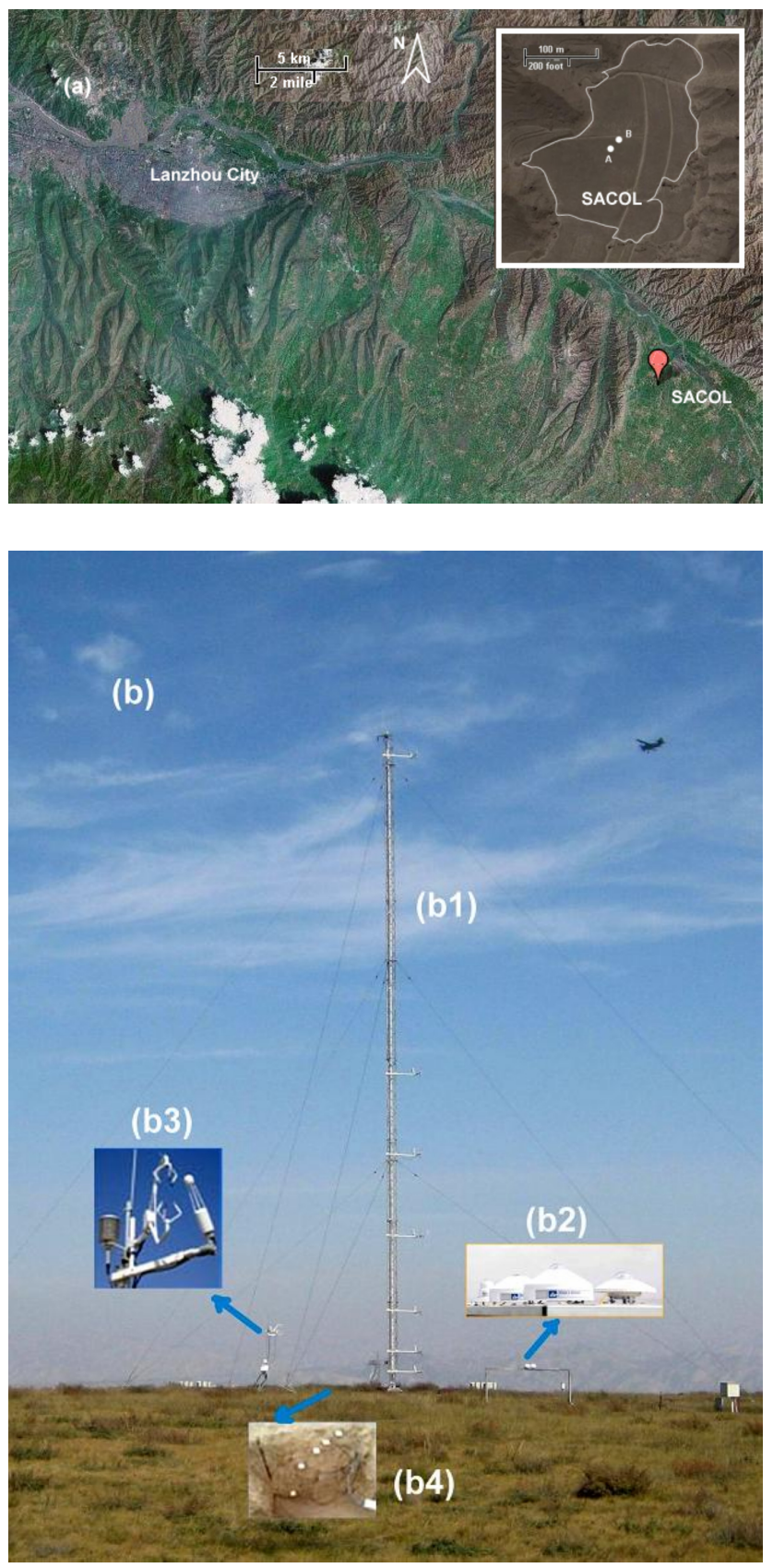

Fig. 1. (a) Topographic map of Lanzhou city, indicating the location of the SACOL site, and with an enlarged image of the site. (b) The SACOL field site, showing vegetation, with boundary layer meteorological tower (1b1), surface radiation monitoring (1b2), eddycovariance system (1b3) and soil monitoring system (1b4).

outgoing shortwave radiation, and upward and downward pyrgeometers for incoming and outgoing longwave radiation. Signals are also recorded to a Campbell CR23X data logger at 2-second intervals, and averaged over 30-min for output data. The installation height of this system is $1.5 \mathrm{~m}$.
3. Eddy-covariance system. This system includes a threeaxis sonic anemometer, and an open-path infrared $\mathrm{CO}_{2} / \mathrm{H}_{2} \mathrm{O}$ analyser, at a measurement height of $3.0 \mathrm{~m}$. These signals are logged to a Campbell CR5000 data logger at $10 \mathrm{~Hz}$.

4. Soil monitoring system. This system includes soil heat flux measurements at the depths of -5 and $-10 \mathrm{~cm}$, moisture measurements at depths of $-5,-10,-20$, -40 , and $-80 \mathrm{~cm}$, and temperature measurements at depths $-2,-5,-10,-20,-50$ and $-80 \mathrm{~cm}$. This data is outputted at a 30-min average. Detailed descriptions of the equipment and installation are given in Table 1.

The present study was conducted using 2006-2010 datasets from SACOL. Qian (1991) pointed out two main characteristics of the local climate around SACOL, as follows: there are clearly four seasons, and total accumulated precipitation in summer and autumn; the wet seasons in the Loess Plateau amount to more than $80 \%$ of the yearly total. Therefore, the year was divided into spring (March-May), summer (June-August), autumn (September-November), and winter (December-February) in this article.

\subsection{Method for analysis of surface energy closure}

The surface energy balance is described by the equation:

$\mathrm{LE}+H_{\mathrm{s}}=R_{\mathrm{n}}-G_{0}-S-Q$

where $R_{\mathrm{n}}$ is net radiation, LE is latent heat flux, $H_{\mathrm{S}}$ is sensible flux, $G_{0}$ is surface soil heat flux, $S$ is canopy heat storage (includes heat storage in above-ground biomass, $S_{\text {plant }}$ and heat storage in the canopy air space, $S_{\text {air }}$, i.e. $S=S_{\text {plant }}+S_{\text {air }}$ ), and $Q$ is the total of additional energy sources/sinks, which may include vertical flux divergence, horizontal advection, photosynthesis, and water pumping (Oncley et al., 2007).

According to SACOL's vegetation and the existing research results, we ignored the biomass heat storage, $S_{\text {plant }}$, as per Wilson et al. (2002), and the total additional energy sources/sinks, $Q$, in this study, then $S=S_{\text {air }}$. The surface energy balance equation can then be expressed as:

$\mathrm{LE}+H_{\mathrm{S}}=R_{\mathrm{n}}-G_{0}-S$.

The left side of the equation is observational turbulent flux, and the right side is surface available energy. The residual energy, $R_{\mathrm{es}}$, is denoted by the equation in the case of $\mathrm{EBC}$ :

$R_{\mathrm{es}}=R_{\mathrm{n}}-H_{\mathrm{s}}-\mathrm{LE}-G_{0}-S$.

Schemes for analysing EBC are many. On the whole, they fall into four types, consisting of (1) least squares for linear regression coefficient (OLSs), (2) the reduced major axis (RMA) method, (3) moment methods (Mms), and (4) energy closure rate (EBR), as presented in Wilson et al. (2002). This study investigates EBC using the least squares scheme 
Table 1. Equipment installed at the SACOL station.

\begin{tabular}{|c|c|c|c|c|}
\hline Monitoring system & Sensor & Model & Manufacturer & Installation (a.g.l.) \\
\hline \multirow[t]{4}{*}{ Tower measurements } & Wind speed sensor & 014A_L & Met One & $(1,2,4,8,12,16,32) \mathrm{m}$ \\
\hline & Wind direction sensor & 034B_L & Met One & $8 \mathrm{~m}$ \\
\hline & Temperature and humidity probe & HMP45C-L & Vaisala & $(1,2,4,8,12,16,32) \mathrm{m}$ \\
\hline & Barometric pressure sensor & CS105 & Vaisala & $1 \mathrm{~m}$ \\
\hline \multirow[t]{2}{*}{ Radiation measurement } & Pyranometer (short-wave radiation) & CM21 & Kipp \& Zonen & $1.5 \mathrm{~m}$ \\
\hline & Pyrgeometer (long-wave radiation) & CG4 & Kipp \& Zonen & $1.5 \mathrm{~m}$ \\
\hline \multirow[t]{2}{*}{ Surface turbulence flux measurement } & 3-D Sonic anemometer & CSAT3 & Campbell & $3 \mathrm{~m}$ \\
\hline & Opened path infrared $\mathrm{CO}_{2} \& \mathrm{H}_{2} \mathrm{O}$ analyzer & LI-7500 & Li-Cor & $3 \mathrm{~m}$ \\
\hline \multirow[t]{3}{*}{ Soil monitoring system } & Water content reflectometer & CS616-L & Campbell & $(-5,-10,-20,-40,-80) \mathrm{cm}$ \\
\hline & Soil temperature profile & STP01-L50 & Hukseflux & $(-2,-5,-10,-20,-50,-80) \mathrm{cm}$ \\
\hline & Soil heat flux plate & HFP01SC-L50 & Hukseflux & $(-5,-10) \mathrm{cm}$ \\
\hline
\end{tabular}

for finding the linear regression coefficient of turbulent energy $\left(\mathrm{LE}+H_{\mathrm{S}}\right)$ against the independently derived available energy $\left(R_{\mathrm{n}}-G_{0}-S\right)$, in order to obtain a linear equation: $\mathrm{LE}+H_{\mathrm{S}}=a\left(R_{\mathrm{n}}-G_{0}-S\right)+b$, where $a$ is the OLS slope, $b$ is the intercept. Here, the OLS slope can characterise the EBC. For the OLS scheme, the idealised EBC is obtained when the intercept is 0 and the slope is 1 .

\subsection{Calculating turbulent flux}

In this paper, the software EdiRe, freely available online at http://www.geos.ed.ac.uk/abs/research/micromet/ Edire/, was employed to deal with the EC data at SACOL. EdiRe is a very complete software package from the University of Edinburgh, which includes all options necessary for processing eddy-covariance data. EdiRe includes the following processing steps:

1. test plausibility;

2. spike removal (e.g. Vickers and Mahrt, 1997);

3. auto detection of time delay between different sensors cross wind; correction of sonic temperature (Liu et al., 2001);

4. planar fit method for coordinate rotation (Wilczak et al., 2001);

5. spectral corrections (Moore, 1986);

6. conversion of the buoyancy flux into sensible heat flux (Schotanus et al., 1983);

7. WPL correction (Webb et al., 1980).

The averaging period of 30 min was adopted for the flux computation in this paper, with exception of the Ogive-analysis.

\subsection{Flux data quality assurance and quality control}

The following three measures were taken in order to ensure quality assurance and control for the flux data:

1. Data exclusions due to underlying surface: data when the surface was covered by snow were excluded, because the underlying surface is much different when covered by snow or ice as compared to grass.

2. Steady state test and integral turbulence characteristics test: because of diverse causes, the dataset had invalid measurements due to their non-steady state and deviation from turbulence characteristics. These invalid data were eliminated before the flux characteristics were analysed. Final quality was obtained on the basis of the steady-state test (SST) and integral turbulence characteristics (ITC) test (Foken and Wichura, 1996). The SST and ITC results, in combination with quality control standards (Foken et al., 2004) as shown in Table 2, were then used to process the 2006-2010 SACOL data for quality assessment and control. Data of final quality flag 7-9 were erroneous and therefore excluded. The ITC test model result used in this work is the parameterization finding of Merry and Panofsky (1976) and the ITC test was done only on the vertical wind component $w$.

3. Footprint analysis: the EC is based on assumptions such as the need for a horizontally homogeneous surface, steady-state flow, and no advection, but the actual underlying conditions cannot achieve such an ideal situation. Thus, when the underlying surface is heterogeneous, the quality of the observation dataset may be compromised. Footprint analysis can be used as a quality assessment tool for eddy-covariance measurements to control the effect of the underlying surface heterogeneity (Göckede et al., 2004). In this paper, footprint calculations were carried out using the Kormann 
Table 2. Classification scheme and deviations of the data quality for the final flag system, steady state test (SST) and integral turbulence characteristics test (ITC-test) after Foken et al. (2004).

\begin{tabular}{lll}
\hline $\begin{array}{l}\text { Final } \\
\text { flag }\end{array}$ & $\begin{array}{l}\text { SST flag } \\
\text { (deviation } \\
\text { in \%) }\end{array}$ & $\begin{array}{l}\text { ITC-test flag } \\
\text { (deviation } \\
\text { in \%) }\end{array}$ \\
\hline 1 & $1(0 \sim 15 \%)$ & $1-2(0 \sim 30 \%)$ \\
2 & $2(16 \sim 30 \%)$ & $1-2(0 \sim 30 \%)$ \\
3 & $1-2(0 \sim 30 \%)$ & $3-4(31 \sim 75 \%)$ \\
4 & $3-4(31 \sim 75 \%)$ & $1-2(0 \sim 30 \%)$ \\
5 & $1-4(0 \sim 75 \%)$ & $3-5(31 \sim 100 \%)$ \\
6 & $5(76 \sim 100 \%)$ & $\leq 5(0 \sim 100 \%)$ \\
7 & $\leq 6(0 \sim 250 \%)$ & $\leq 6(0 \sim 250 \%)$ \\
8 & $\leq 8(0 \sim 1000 \%)$ & $\leq 8(0 \sim 1000 \%)$ \\
9 & $*(>1000 \%)$ & $*(>1000 \%)$ \\
\hline
\end{tabular}

and Meixner footprint model (Kormann and Meixner, 2001). The flux contributions in percentage (fp) from the target zone had been computed and classified into 7 levels by a previous study (Göckede et al., 2004). Fp class 1 is related to $100 \%$ contribution, class 2 to 95-99.9\%, class 3 to $90-94.9 \%$, class 4 to $80-89.9 \%$, class 5 to $70-79.9 \%$, class 6 to $50-69.9 \%$, and class 7 to less than $50 \%$. Data in class 7 are not strong enough to be valid (Göckede et al., 2008); therefore, data of class 7 are excluded. The mean values of the flux contribution calculated at the SACOL site were more than $80 \%$ in all seasons except winter. Figure 2 is the classified distribution of the flux contribution. It can be seen from this figure that the flux contribution equal to $100 \%$ only accounts for a small portion of the total data, with about $1.0 \%$ in winter, and less than $1.0 \%$ in the other seasons. Data of flux contribution equal to and greater than $50 \%$ account for the majority of the data, but data of flux contribution less than $50 \%$ are of low quality, and need to be removed from the dataset. This part of the data is only a small proportion of the dataset, with about $12.0 \%$ in winter and less than $10 \%$ in the other seasons. Valid data accounted for 77.6, 75.4, 68.3 and $51.9 \%$ of the total amount of data, for spring, summer, autumn and winter, after eliminating data in the quality control.

\subsection{Calculation of storage heat flux}

The air-space heat storage flux in the air-column below the height of the surface turbulence flux measurement include sensible and latent heat storage flux, i.e. $S_{\text {air }}=S_{T}+S_{q}$.

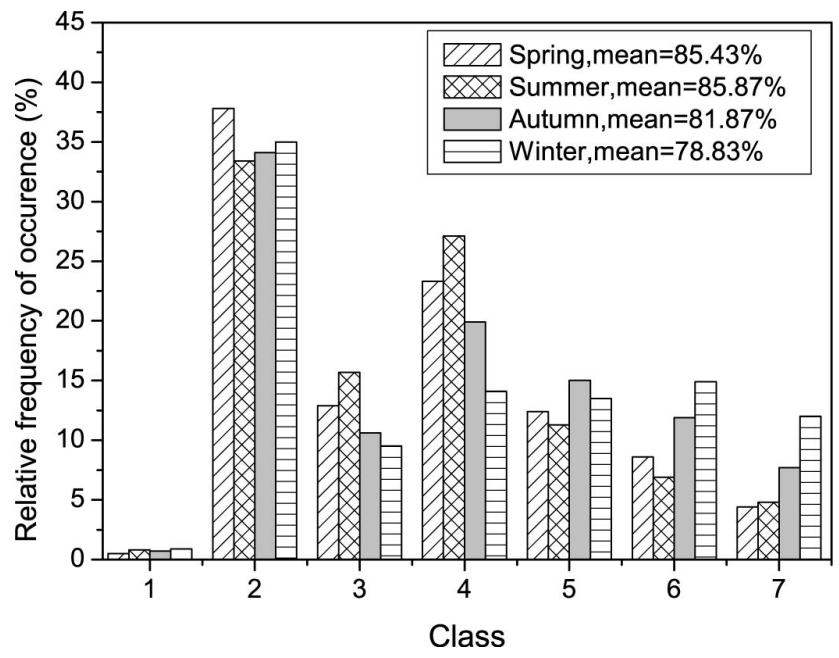

Fig. 2. The seasonal classified distribution of the flux contribution calculated at SACOL site. Class 1: the flux contributions in percentage from the target zone is $100 \%$; class 2: 95-99.9\%; class 3: 90-94.9\%; class 4: 80-89.9\%; class 5: 70-79.9\%; class 6: $40-$ $69.9 \%$; class $7:<50 \%$.

The sensible heat storage flux in the canopy airspace $\left(S_{T}\right)$ was calculated following (McCaughey, 1985):

$S_{T}=\int_{0}^{z_{r}} \rho c_{p} \frac{\mathrm{d} T}{\mathrm{~d} t} \mathrm{~d} z \approx \rho c_{p} \sum_{i=1}^{n}\left(\frac{\Delta T_{\mathrm{a}}}{\Delta t} \Delta z_{i}\right)$

where $\rho$ is the air density, $c_{p}$ is the specific heat of air, $z_{r}$ is the height of the surface turbulence flux measurement, $T$ is air temperature in the air-column below $z_{r}$, and $T_{\mathrm{a}}$ is a representative layer-average of $T$ in each of several layers. $T_{\mathrm{a}}$ was measured at three levels $(1,2,3 \mathrm{~m}$, where $3 \mathrm{~m}$ is the mean of $2 \mathrm{~m}$ and $4 \mathrm{~m}$ ) using HMP45-L thermistors below $z_{r} . S_{T}$ was calculated by summing Eq. (4) through the three levels of temperature measurements using 30-min increments.

The latent heat storage flux $\left(S_{q}\right)$ was calculated following (McCaughey, 1985):

$S_{q}=\int_{0}^{z_{r}} \frac{\rho c_{p}}{\gamma} \frac{\mathrm{d} e}{\mathrm{~d} t} \mathrm{~d} z \approx \rho L_{e} \sum_{i=1}^{n}\left(\frac{\Delta e_{i}}{\Delta t} \Delta z_{i}\right)$.

$L_{e}$ is the latent heat of vaporization, $e$ is vapor pressure, which calculated from $T_{\mathrm{a}}$ and relative humidity measurements.

Seasonally ensemble averaged daily variation of halfhourly values of sensible and latent heat storage flux are shown in Fig. 3. As can be seen in the figure, the magnitudes of sensible heat storage flux have obvious characteristics of diurnal variation, which are positive (negative) during the daytime (nighttime). The range of $S_{T}$ peaks is only $1.5-2.0 \mathrm{~W} \mathrm{~m}^{-2}$, and the ratio of the net radiation is about $0.3-0.6 \%$. The magnitudes of latent heat storage flux are so small that they can be neglected completely. The fluctuated range of $S_{q}$ is only $\pm 0.5 \mathrm{~W} \mathrm{~m}^{-2}$. Therefore, the term 


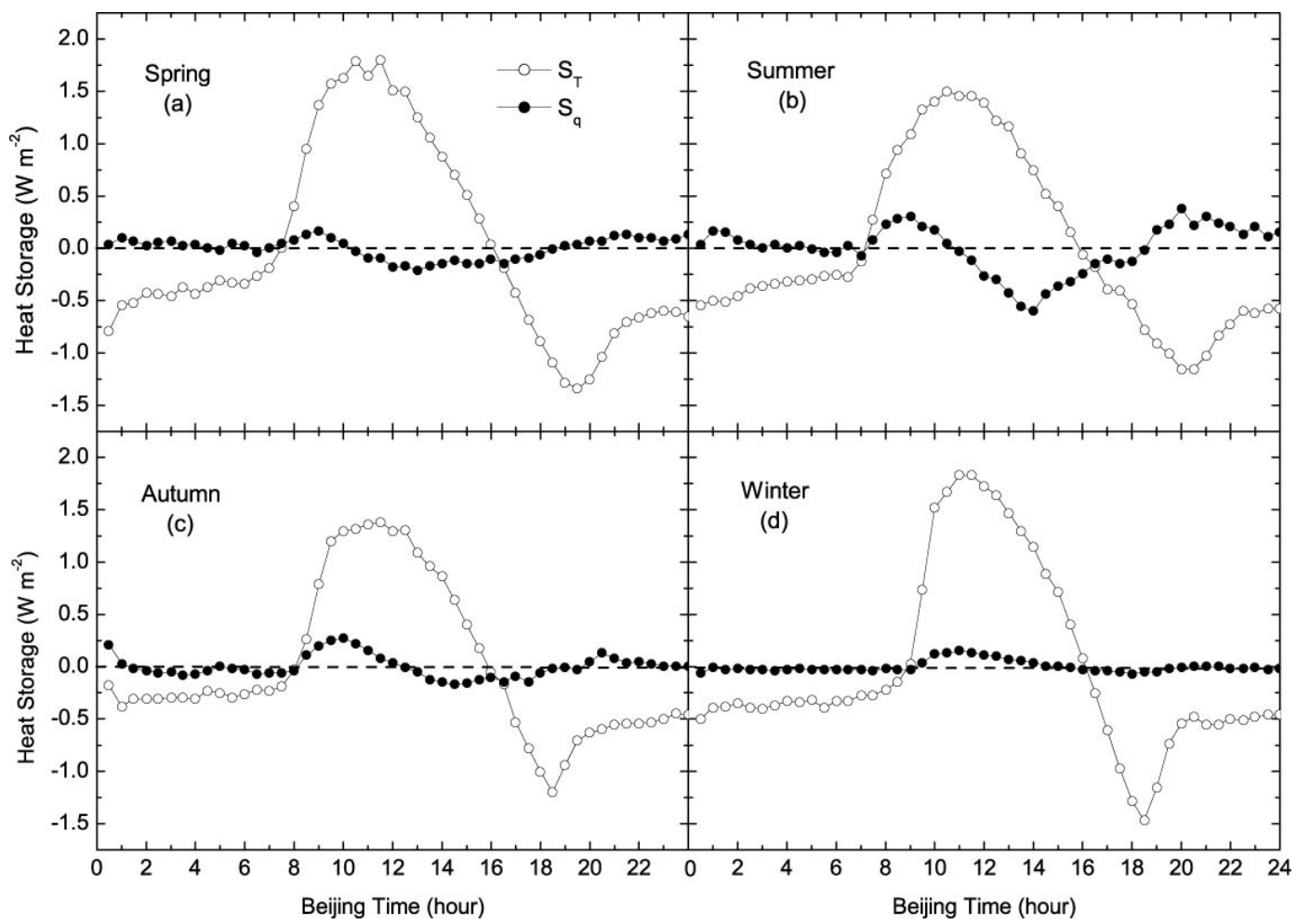

Fig. 3. Seasonally averaged diurnal cycle of the components of air-space storage heat flux over the native grassland of the semi-arid Loess Plateau in (a) spring, (b) summer, (c) autumn, and (d) winter. Where $S_{T}$ is the sensible heat storage flux, $S_{q}$ is the latent heat storage flux.

of $S_{\text {air }}$ could not influence the EBC basically over the semiarid Loess Plateau. That the storage heat flux term could be ignored in the short grass air space was proved further by comparing with the result of Wilson et al. (2002). So, the Eqs. (2) and (3) could be simplified to the expressions:

$\mathrm{LE}+H_{\mathrm{S}}=R_{\mathrm{n}}-G_{0}$

$R_{\mathrm{es}}=R_{\mathrm{n}}-H_{\mathrm{s}}-\mathrm{LE}-G_{0}$.

\subsection{Calculation schemes for surface soil heat flux}

$G_{0}$ is surface soil heat flux (SSHF) in the energy balance equation, but the measured soil heat flux $G(z)$ is usually measured under the soil at a certain depth, $z$. Therefore, we need to consider the soil heat storage, $S_{\text {soil }}$, and obtained the surface soil heat flux by calculation. There are various schemes to calculate SSHF (Fuchs, 1986). The combination of heat flux plate measurements and calorimetry ("PlateCal" approach, Liebethal et al., 2005) and Thermal Diffusion Equation and Correction ("TDEC" approach, Yang and Wang, 2008) were employed to calculate SSHF in this study. The PlateCal and TDEC approaches are briefly introduced below.

The expression for a 1-D soil thermal diffusion equation is

$\frac{\partial \rho_{\mathrm{s}} c_{\mathrm{S}} T}{\partial t}=\frac{\partial G}{\partial z}$
$G=\lambda_{\mathrm{s}} \frac{\partial T}{\partial z}$

where $t(\mathrm{~s})$ is the time, $z(\mathrm{~m})$ the soil depth, $T(\mathrm{~K})$ the soil temperature, $\rho_{\mathrm{s}} c_{\mathrm{S}}\left(\mathrm{J} \mathrm{kg}^{-1} \mathrm{~K}^{-1}\right)$ is the soil heat capacity, $\lambda_{\mathrm{s}}$ $\left(\mathrm{W} \mathrm{K}^{-1} \mathrm{~m}^{-1}\right)$ the soil thermal conductivity and $G\left(\mathrm{~W} \mathrm{~m}^{-2}\right)$ is the soil heat flux. After integration, we have

$G(z)=G\left(z_{\text {ref }}\right)+\frac{\partial S}{\partial t}=G\left(z_{\text {ref }}\right)+\int_{z_{\text {ref }}}^{z} \frac{\partial \rho_{\mathrm{s}} c_{\mathrm{s}} T(z)}{\partial t} \mathrm{~d} z$

where $G\left(z_{\text {ref }}\right)$ represents the soil heat flux in a given reference layer. Given the temperature profile $T\left(z_{\mathrm{i}}\right)$, the discrete form of the integral expression is

$$
\begin{aligned}
G(z, t)= & G\left(z_{\text {ref }}, t\right)+\frac{1}{\Delta t} \sum_{z_{\text {ref }}}^{z}\left[\rho_{\mathrm{S}} c_{\mathrm{S}}\left(z_{\mathrm{i}}, t+\Delta t\right)\right. \\
& \left.T\left(z_{\mathrm{i}}, t+\Delta t\right)-\rho_{\mathrm{S}} c_{\mathrm{S}}\left(z_{\mathrm{i}}, t\right) T\left(z_{\mathrm{i}}, t\right)\right] \Delta z
\end{aligned}
$$

where

$$
\begin{aligned}
\rho_{\mathrm{S}} c_{\mathrm{S}}(z, t) & =c_{v}(z, t)=2.1 \times 10^{6}\left(1-\theta_{\mathrm{sat}}\right) \\
& +4.19 \times 10^{6} \theta(z, t) \mathrm{J} \mathrm{m}^{-3} \mathrm{~K}^{-1}
\end{aligned}
$$

with $\theta_{\text {sat }}\left(\mathrm{m}^{3} \mathrm{~m}^{-3}\right)$ denotes the soil porosity and $\theta\left(\mathrm{m}^{3} \mathrm{~m}^{-3}\right)$ denotes the water content in a unit volume of soil (Sellers et al., 1996). 


\subsubsection{The PlateCal approach}

This technique involves setting a heat flux plate at a particular depth, $z_{\text {ref }}$, in order to measure the flux at that depth. The surface soil heat flux, $G_{0}$, is then obtained by integrating heat from the reference level to the surface, i.e. we took $z=0.0 \mathrm{~m}$ in Eq. (10) for use, leading to

$G_{0}(\mathrm{PC})=G_{\text {Plate }}+\frac{\partial S}{\partial t}=G_{\text {Plate }}+\int_{z_{\text {zef }}}^{0} \frac{\partial \rho_{\mathrm{s}} c_{\mathrm{s}} T(z)}{\partial t} \mathrm{~d} z$.

Here, the heat storage is calculated with the directly measured soil temperature. The SACOL heat flux plate (HFPOISC-L, Hukseflux) is capable of automatic on-line correction which improves the accuracy of the measurements. The plate avoids the sudden failure of matching between the probe and heat conductivity coefficient or any abrupt change in water content that would result in a change in the soil heat conduction coefficient, leading to measurement error. Surface temperature, $T_{0}$, was obtained through the conversion of incoming and outgoing long-wave radiation, i.e. by way of

$T_{0}=\left[\left(R_{\mathrm{lw}}^{\uparrow}-\left(1-\varepsilon_{g}\right) R_{\mathrm{lw}}^{\downarrow}\right) /\left(\varepsilon_{g} \sigma\right)\right]^{1 / 4}$

where $\sigma$ is the Stefan-Boltzman constant $\left(5.67 \times 10^{-8} \mathrm{~W}\right.$ $\left.\mathrm{m}^{-2} \mathrm{~K}^{-4}\right), \varepsilon_{g}$ is surface reflectivity $\left(0<\varepsilon_{g} \leq 1\right)$, and $R_{\mathrm{lw}}^{\uparrow}$ and $R_{\mathrm{lw}}^{\downarrow}$ denote, respectively, the outgoing and incoming longwave radiation. Here, $\varepsilon_{g}$ is given empirically, and is set to 0.98 for convenience.

\subsubsection{The TDEC approach}

With the TDEC approach, the key issue is how to get a reliable temperature profile and soil thermal conductivity from finite observations. The discrete form of Eq. (11) about the new linear interpolation method can be represented by a tridiagonal system (Eq. 15a-c):

For the 1st layer,

$T_{1}=T_{\text {sfc }}$.

For the $i$-th layer,

$A_{i} T_{i}^{t+\Delta t}=B_{i} T_{i+1}^{t+\Delta t}+C_{i} T_{i-1}^{t+\Delta t}+D_{i}$

where

$$
\begin{aligned}
A_{i} & =\frac{1}{2} \rho_{\mathrm{s}} c_{\mathrm{s}, i}\left(\Delta z_{\mathrm{i}-1}+\Delta z_{\mathrm{i}}\right)+\frac{\lambda_{\mathrm{s}, i-1} \Delta t}{\Delta z_{\mathrm{i}-1}}+\frac{\lambda_{\mathrm{s}, i} \Delta t}{\Delta z_{\mathrm{i}}}, \\
B_{i} & =\frac{\lambda_{\mathrm{s}, i} \Delta t}{\Delta z_{\mathrm{i}}} \\
C_{i} & =\frac{\lambda_{\mathrm{s}, i-1} \Delta t}{\Delta z_{\mathrm{i}-1}}
\end{aligned}
$$

and,

$D_{i}=\frac{1}{2} \rho_{\mathrm{s}} c_{\mathrm{s}, i}\left(\Delta z_{\mathrm{i}-1}+\Delta z_{\mathrm{i}}\right) T_{i}^{t}$.

For the $n$-th layer,

$T_{n}=T_{\mathrm{bot}}$

in which $T_{\mathrm{sfc}}$ and $T_{\mathrm{bot}}$ represent temperature at surface and bottom level, respectively, as the boundary conditions of the equation. This is because soil temperature varies dramatically in the top soil, we used stretching computational nodes, i.e. a layer near the surface is thinner than that in the deep soil. The layer thickness is given as is shown in Eq. $(15 \mathrm{a}-\mathrm{c})$ :

$\Delta z_{1}=D\left(e^{\xi}-1\right) /\left(e^{n \xi}-1\right)$

$\Delta z_{i}=e^{\xi(i-1)} \Delta z_{1}$

where $D$ is the model domain, and $\xi$ is a stretching parameter. If $\xi=0$, the node spacing becomes uniform.

With iteration, the soil temperature profile can be calculated with the thermal diffusion equation (Eq. 8) first by using an estimated value of the soil thermal conductivity, and then by adjusting the soil thermal conductivity according to the differences between the observed and computed soil temperatures. By this method, the soil temperature profile can be upgraded, and a reliable temperature profile and the soil thermal conductivity can be obtained. Finally, the soil flux was calculated with Eq. (13).

\subsection{Relative turbulence intensity}

Turbulence intensity is one of the most important parameters to describe the characteristics of atmospheric turbulence motion, which is the ratio of the wind speed standard deviation to the average wind speed. To avoid abnormally large values of the vertical turbulence intensity from being derived from small wind speeds, the relative vertical turbulence intensity, $\mathrm{RI}_{w}$, is used. $\mathrm{RI}_{w}$ is defined as:

$\mathrm{RI}_{w}=\frac{\sqrt{\overline{\overline{w^{\prime 2}}}}}{\sqrt{\overline{\overline{w^{\prime 2}}}+\bar{U}}}$

where $\bar{U}$ denotes the mean horizontal wind, and $\sqrt{\overline{w^{\prime 2}}}$ is the standard deviation of the vertical wind speed. The higher $\mathrm{RI}_{\mathrm{w}}$ is, the more the turbulence develops. By investigating the relationship between turbulence intensity and $\mathrm{EBC}$, the effect on EBC of atmospheric turbulence motion can be understood.

\section{Results and discussion}

\subsection{Analysis of surface energy balance characteristics}

To investigate the surface energy balance and its residual energy on a seasonal scale, half-hourly datasets were established. Figure 4 depicts the seasonal mean diurnal cycles of 


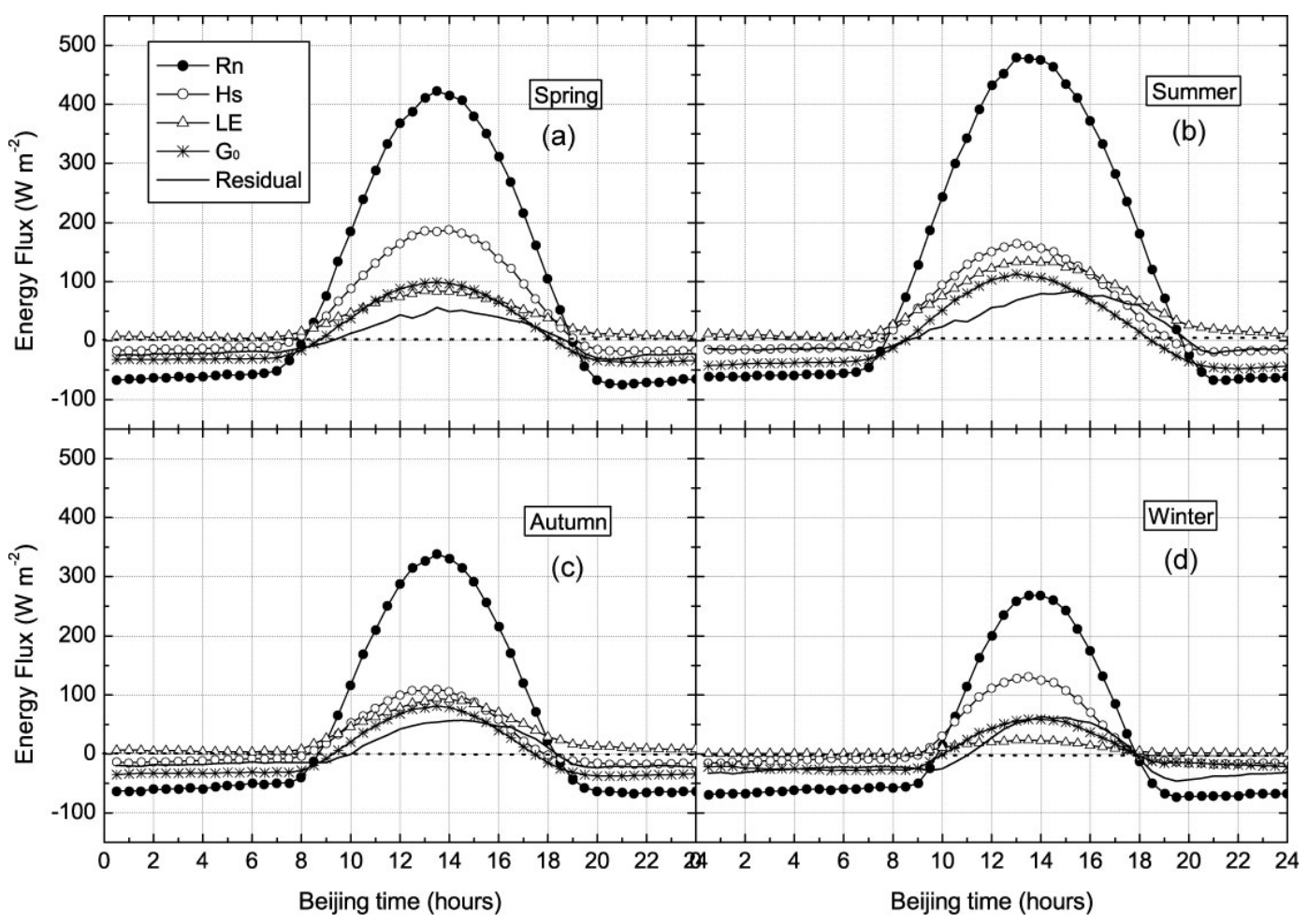

Fig. 4. Seasonally averaged diurnal cycle of the components of energy balance over the native grassland of the semi-arid Loess Plateau in (a) spring, (b) summer, (c) autumn, and (d) winter.

$R_{\mathrm{n}}, H_{\mathrm{s}}, \mathrm{LE}, G_{0}$, and $R_{\mathrm{es}}$, where the surface soil heat flux was calculated with the PlateCal method. As illustrated in Fig. 4a and $\mathrm{d}$, the magnitudes of spring and winter sensible heat flux $\left(H_{\mathrm{s}}\right)$ are positive (negative) during the daytime (night-time), while the latent heat flux (LE) is positive the whole day, with much smaller values at night, suggesting weak evaporation at the surface. The $H_{\mathrm{S}}$ is distinctly larger than the LE in spring and winter, with the energy transport dominated by $H_{\mathrm{s}}$ in the near-surface layer; LE is particularly smaller in winter. As illustrated in Fig. 4b and c, the diurnal cycles of the summer and autumn heat fluxes are very similar to those in spring and winter (Fig. 4a and d). In summer and autumn, however, $H_{\mathrm{s}}$ matches LE in energy exchange; LE is augmented owing to the seasonal rainfall and strong evaporative ability. The energy balance, however, is clearly not closed and the residual part of the energy balance is too large to be ignored. Figure 5 is yearly variation of the daily means of several meteorological variables over the native grassland of the semiarid Loess Plateau. The seasonal variation characteristics of the variables are obvious according to the division method of the four seasons in Sect. 2.1. Referring to the long-term variations of meteorological variables (Fig. 5), and the local climate (Qian, 1991), the seasonal mean diurnal cycles of $R_{\mathrm{n}}$, $H_{\mathrm{s}}$, LE, and $G_{0}$ in Fig. 4 clearly represent the main characteristics of interaction between the atmosphere and the land in semi-arid regions, even though energy is not balanced.
The values of the slopes and intercepts for the energy balance as obtained from the linear regression are $0.78,0.74$, $0.72,0.63$ and $17.31,11.53,12.26,16.13 \mathrm{~W} \mathrm{~m}^{-2}$ for spring, summer, autumn and winter, respectively. The energy balance averaged over all seasons thus gives a slope of 0.74 and an intercept of $14.09 \mathrm{~W} \mathrm{~m}^{-2}$ for the whole dataset. Wilson et al. (2002), in a comprehensive study across 22 sites in FLUXNET, reported values of slopes ranging from 0.53 to 0.99 , and intercepts from -33 to $37 \mathrm{~W} \mathrm{~m}^{-2}$. Figure 6 shows the seasonal residual energy with standard deviation and EBC. As shown in Fig. 6, the standard deviation is greater during the day than the night across all seasons, and is largest in summer, and smallest in winter. Although the residuals are different from season to season, some common characteristics are apparent, as follows:

a. The residual part of the energy balance displayed appreciable diurnal variation. It is negative at night, which means the available energy is lower than turbulent energy at that time. The positive values of the residual during the day mean that the available energy exceeds turbulent energy at that time.

b. The energy closure rises to the highest state in the morning, which is maintained for several hours, and then descends to a lower state at the night. Energy closure reaches a minimum in the early morning. This pattern was also observed by Oliphant et al. (2004) in a 

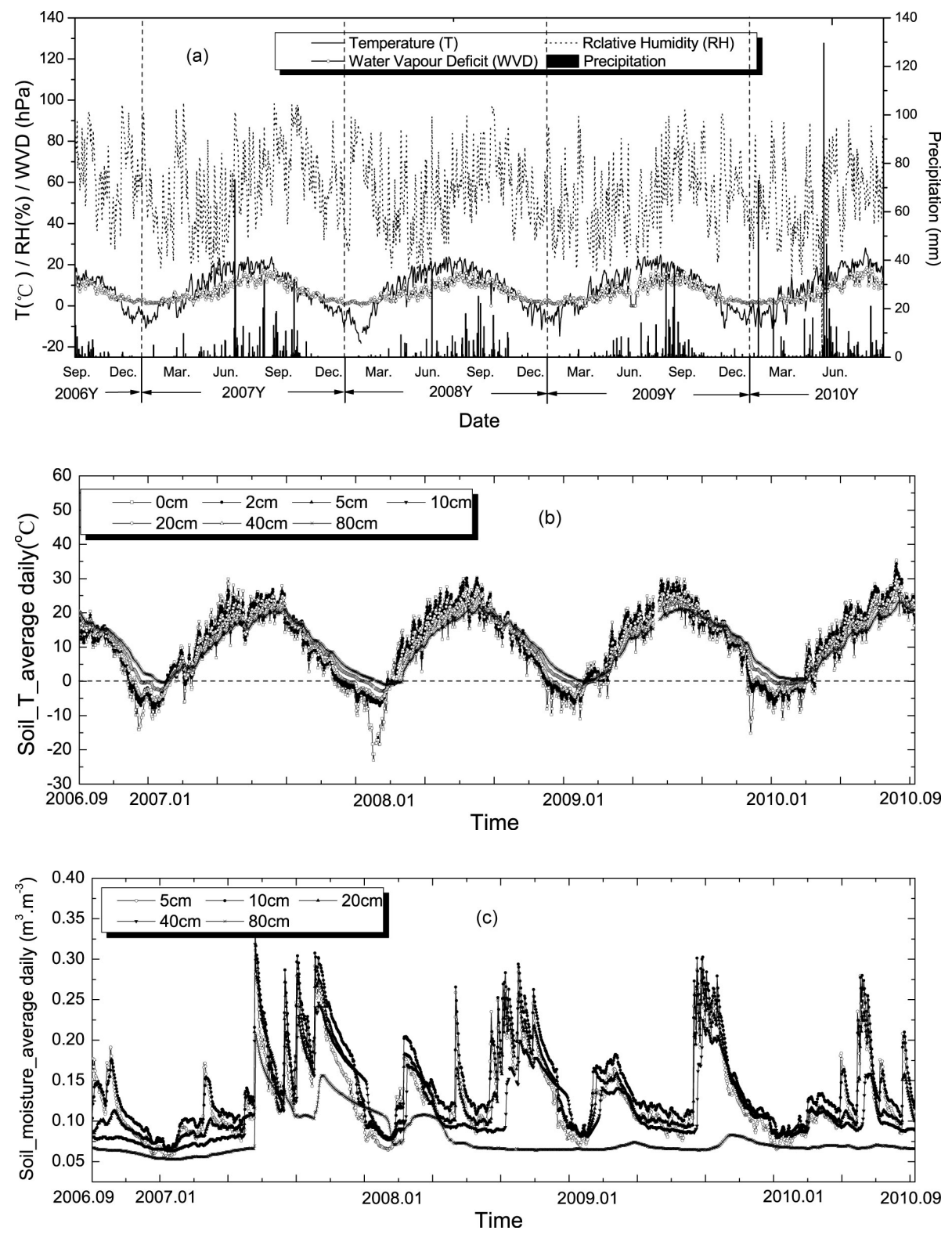

Fig. 5. Yearly variation of the daily means of several meteorological and hydrological variables over the native grassland of the semi-arid loess plateau: (a) temperature, relative humidity, water vapour deficit and precipitation; (b) soil temperature; (c) soil moisture.

southcentral Indiana (USA) forest and by Sánchez et al. (2010) in a Sodankyla (Finland) forest.

c. It is very hard to balance the energy, especially at night. The energy closure achieves balance for only a few hours; thus, EBC is still a serious problem to be considered.

To a certain extent, these results show that the long-term micro-meteorological observations, including the equipment and data analysis methods, are successful. The observation data could display correctly in the seasonal characteristics of the surface energy balance. The results also indicate that the residual and the energy closure must be stable, and that the factors that have impact on the energy closure are also stable and have no seasonal variability.

Some authors (Foken et al., 2006; Cava et al., 2008; Wilson et al., 2002) have discussed possible causes for this lack of energy balance since it is clear that the problem is more than just the result of statistical errors. To determine potential reasons for energy balance unclosure, the effects of diverse schemes for surface soil heat flux, the flux contribution from the target area, the loss of low-frequency part of the turbulence spectra, and the turbulent mixing are discussed in the following sections. 

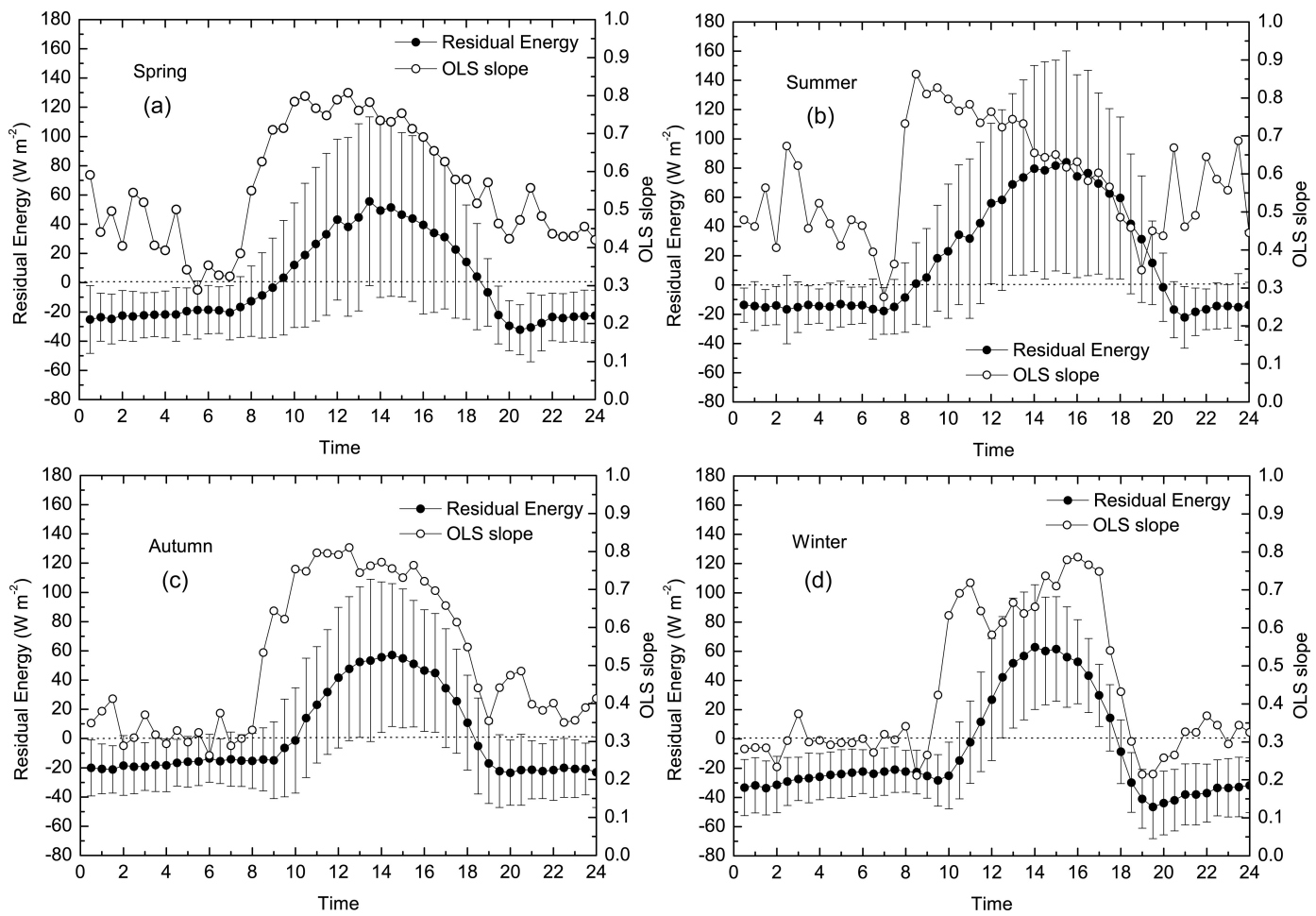

Fig. 6. Seasonal average diurnal variation of the residual energy computed on the basis of the surface ground heat flux calculated using the PlateCal approach at SACOL site in (a) spring, (b) summer, (c) autumn, and (d) winter. The bars represent the standard deviation of the mean.

\subsection{Effect of calculated surface soil heat flux on EBC}

The scheme for calculating SSHF and its accuracy, which is likely to directly affect the surface EBC, is certainly worthy of our attention. The schemes introduced in Sect. 2.5 were used to investigate the impact on the EBC of the calculated SSHF. The EBC effect of soil heat flux at a depth of $5 \mathrm{~cm}$ and that of the PlateCal- and TDEC-calculated SSHF were compared on a seasonal basis, as shown in Fig. 7. As seen in Fig. 7, the EBC obtained from soil heat flux at the depth of $5 \mathrm{~cm}$ is worse than that calculated by the surface soil heat flux in spring, summer, and autumn. In addition, the surface soil heat flux calculated by TDEC shows a better EBC than that by PlateCal during the day, whereas the opposite is generally true at night. There is no difference between the various methods to calculate EBC in the winter. Table 4 gives the slope and intercepts for EBC using the surface soil heat flux that was calculated by the two difference methods and the measurement value at the depth of $5 \mathrm{~cm}$, and illustrates the seasonal characteristics of EBC for the semi-arid Loess Plateau of Northwest China with native grassland as the underlying surface. As shown in Table 4, the use of the PlateCal-calculated SSHF instead of the plate-measured heat flux resulted in EBC improvement in each season, with increases of $12,9,10$, and $8 \%$ respectively for spring, summer, autumn and winter. On the other hand, the TDEC-obtained
SSHF utilised in EBC analysis increased 5, 5, and $4 \%$ in spring, summer and autumn, but decreased and $2 \%$ for the winter. In fact, the difference of EBC is caused by soil heat storage between soil layer at the depth of $5 \mathrm{~cm}$ and the surface soil layer. It is hence obvious that EBC obtained without soil heat storage correction will be poorer. These results show that soil storage is very important to the energy balance. Furthermore, from Fig. 7 it is evident that PlateCal and TDEC yield in practice same results in terms of EBC and hence when estimated appropriately, the difference in soil heat flux cannot explain the gap in EBC. Because there is a slight difference in the two schemes for SSHF calculation, we could not ignore the impact that the different schemes had on the energy balance. Kukharets et al. (2000) also found that the soil heat flux and the EBC are closely related due to the energy storage in the upper layer of soil. In addition, Heusinkveld et al. (2004) established a new approach to calculate soil heat flux, leading to acceptable EBC. Hence, we believe that a more accurate scheme of SSHF will improve the EBC study in an effective manner. Although the various schemes for SSHF calculation improve the EBC in different ways, as shown in Fig. 7, the EBC variation remains the same; this means that the soil heat flux effect on the EBC is stable. 


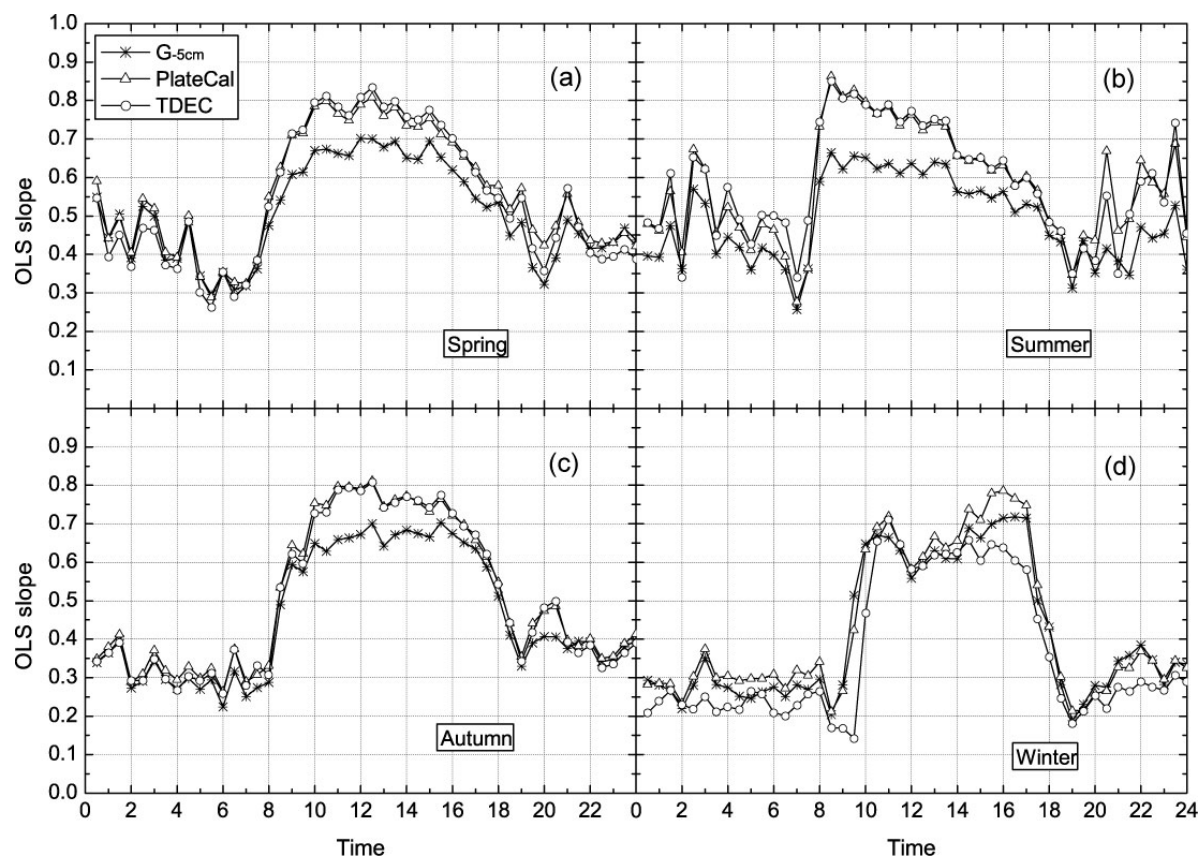

Fig. 7. Comparison between the diurnal variation of seasonal EBC computed by using the ground heat flux measured at a depth of $5 \mathrm{~cm}$, and the surface soil heat flux calculated using PlateCal and TDEC at SACOL site in the (a) spring, (b) summer, (c) autumn, and (d) winter.

\subsection{Effects of target area flux contribution on EBC}

A large flux contribution from the target area indicates that the land surface heterogeneity has a small effect on the flux measured at the observation point; such a flux contribution more accurately describes the actual turbulence (Rebmann et al., 2005).

Any flux measurement performed at a single point is influenced by an effective upwind source area. Obstacles such as trees, the supporting tower, or the measuring devices themselves may disturb the turbulent wind field. Therefore, in order to determine which part of the surrounding surface has the strongest contribution, and what condition has the best EBC, we carried out intensive research concerning the percentage of turbulent flux contributions. This was done for a range of wind directions and stability values $(z-d) / L$ (where $z$ is the measured height and $L$ the Monin-Obukhov length), so as to reveal the optimal portion of the target zone for idealised energy balance.

Figure 8 shows mean percentage contribution of eddycovariance fluxes in differing wind directions and $z / L$ for the four seasons, with flux contributions lower than $50 \%$ removed. It can be clearly seen that, with increased atmospheric stability, flux contributions exhibited reducing trends in all directions, with the maximal (minimal) contribution in intense instability (strong stability). It is clear that for $z / L<-0.2$, the turbulent flux contributions averaged over the target zone in all directions except from the north exceeded $97 \%$. At $-0.2 \leq z / L<-0.0625$, the percentage contributions reached $>90 \%$ in all directions, and even in excess of $95 \%$ in some directions. With $-0.0625 \leq z / L<0.0625$, the contributions exceeded $80 \%$ for all directions, and with $0.0625 \leq z / L<0.2$, the contributions for all directions were greater than $70 \%$, with a major part of the flux contribution exceeding $80 \%$. At $z / L \geq 0.2$, however, these contributions were a great deal smaller in all wind directions. Southeasterly (SE) wind prevail over the Loess Plateau throughout the year, with the next being northwesterly wind (NW). In fact, a higher flux contribution exists for the NW winds. Particularly in the case of strong atmospheric stability, the percentage contribution for the SE wind was small compared with the NW wind in the various seasons. This shows that the underlying homogeneity of the upwind source area in the NW is greater than that in the SE, and also that the representation of the flux observation and the EBC is better for the NW wind. It should be noted that in different seasons, the growth of the grass changes the canopy height; this, however, only changes the zero-plane displacement height, $d$, without changing the status of the underlying surface in the target area.

Figure 9 shows the relationship of the seasonal flux contribution to the EBC (denoted by OLS slope). From the figure, it can be seen that when the percentage contribution increases, the OLS slope does as well, until the flux contribution reaches $100 \%$ (i.e. when the OLS slope is the largest). In the spring, the EBC (OLS slope) for each of the $6 \mathrm{fp}$ classes is larger than 0.50 , and the trend of the OLS slope slowly increases from $50 \%$ to $90 \%$ flux contribution., However, the OLS slope for spring sharply increases for flux contribution over $90 \%$ with a value of 0.87 at $100 \%$ flux contribution. 


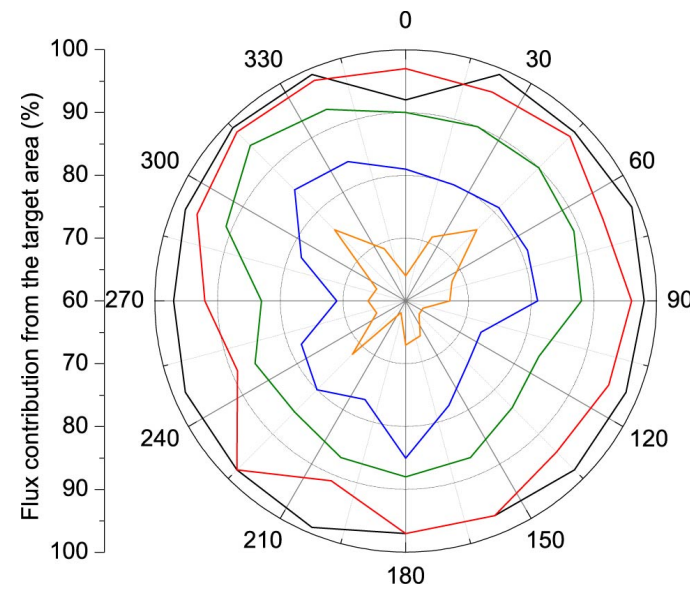

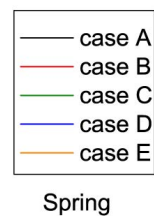

(a)
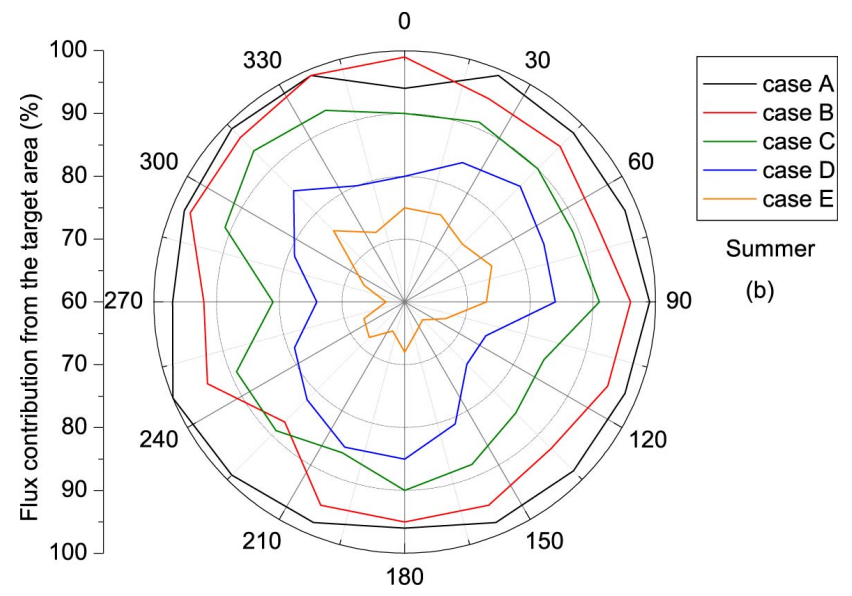

(b)
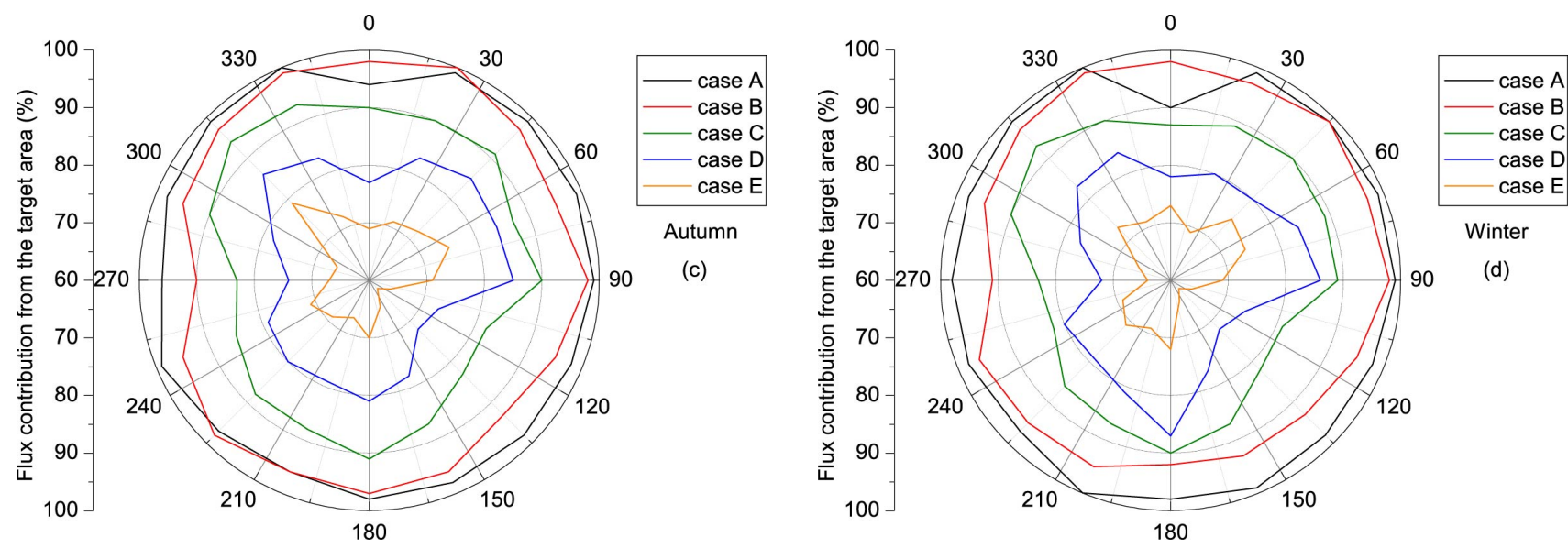

(c)

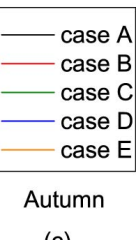

Fig. 8. Eddy covariance flux contribution from the target zone (\%) in different wind directions and stability at SACOL site for (a) spring, (b) summer, (c) autumn, and (d) winter. Case A stands for $\zeta \leq-0.2$, B for $-0.2<\zeta \leq-0.0625$, C for $-0.0625<\zeta \leq 0.0625$, D for $0.0625<\zeta \leq 0.2$, E for $\zeta>0.2$ (the definition of case).

In summer, the smallest OLS slope is about 0.50 , but nevertheless, the OLS slope does not increase as a function of increased flux contribution with the exception of fp class 4 . Here, when the summer flux contribution reaches $100 \%$, the OLS slope is 0.80. On the other hand, the autumnal OLS slope increases significantly with flux contribution; the OLS slope is 0.90 at $100 \%$ flux contribution. There is poor EBC in winter, but the variation of the OLS slope with increasing flux contribution is consistent with the other seasons; with $100 \%$ flux contribution, the OLS slope reaches only 0.70 . In summary, the EBC is different in various seasons, but the positive trend of the EBC with the percentage contribution is consistent across the seasons. This result suggests that the flux contribution effect on the EBC is also stable.

\subsection{Effect of the low-frequency part of the turbulence spectra on EBC}

Foken et al. (2006) came to the conclusion that the EBC was most closely related to the low-frequency part of the turbulence spectra. Thus, an analysis of the impact on the EBC of the low-frequency portion of the turbulence spectra from the SACOL measurements was conducted. The Ogive function, the cumulative integral of the co-spectrum starting with the highest frequencies, is useful when discussing the influence of low-frequency fluxes on surface exchange (Moncrieff et al., 2005). Whether the Ogive curve reaches the asymptotic line is a criterion to judge if enough lowfrequency part of spectra has been captured. This function is expressed as

$\operatorname{Og}_{w x}(f)=\int_{f_{\text {high }}}^{f} \operatorname{Co}_{w x}(f) \mathrm{d} f$

where $\mathrm{Co}_{w x}$ is the co-spectrum of turbulent flux, $w$ is the vertical wind component, $x$ is the horizontal wind component (or scalar), $f_{\text {high }}$ is the Nyquist frequency, $f$ is the frequency larger than the lowest resolution $f_{\text {low }}=(2 T)^{-1}$, and $T$ is the time-series length. To improve the statistical significance, we selected time sequences spaced at $4 \mathrm{~h}$ for analysis, i.e. the series of frequencies higher than approximately $6.9 \times 10^{-6} \mathrm{~Hz}$. 
Table 3. Definition of three different cases for the behaviour of Ogive functions.

\begin{tabular}{ll}
\hline Case & Criterion \\
\hline 1 Convergent ogives within the 30 min interval & $\frac{|\mathrm{Og}(150 \mathrm{~min})|}{\max |\mathrm{Og}|}>0.9$ and $\frac{|\mathrm{Og}(30 \mathrm{~min})|}{\max |\mathrm{Og}|}>0.9$ \\
2 Ogives with a distinct extreme value before a $150 \mathrm{~min}$ integration time & $\frac{|\mathrm{Og}(150 \mathrm{~min})|}{\max |\mathrm{Og}|} \leq 0.9$ \\
3 Not convergent ogive even for $150 \mathrm{~min}$ & $\frac{|\mathrm{Og}(30 \mathrm{~min})|}{\max |\mathrm{Og}|} \leq 0.9$ and $\frac{|\mathrm{Og}(150 \min )|}{\max |\mathrm{Og}|}>0.9$ \\
\hline
\end{tabular}

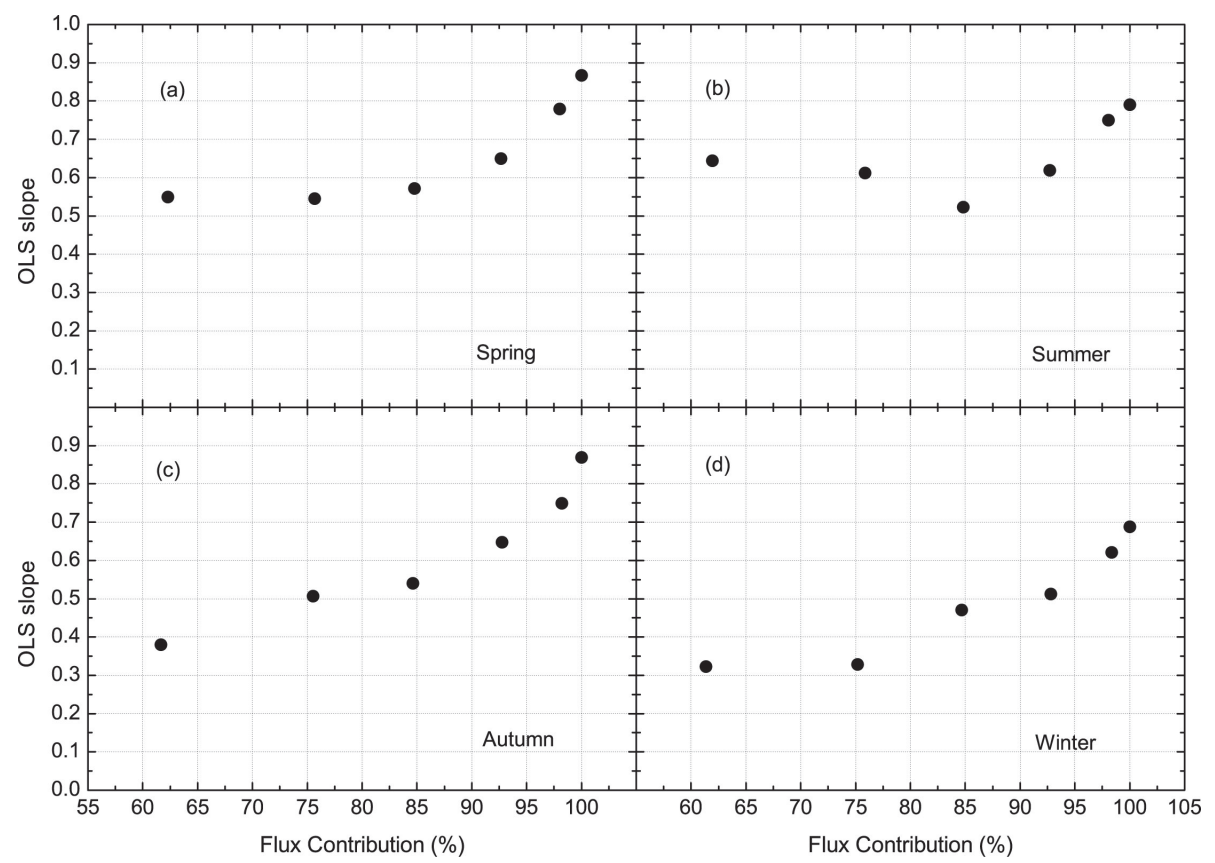

Fig. 9. Seasonal effect of flux contribution from the target zone on energy balance closure denoted as OLS slope in the target zone at SACOL site in (a) spring, (b) summer, (c) autumn, and (d) winter.

In this way, the sequences not only contain the low-frequency turbulence spectra produced by intermittent fluxes, but avoid the loss of partial information due to the diurnal variation of the flux as well.

The 2006-2010 series was divided into sequences of $4 \mathrm{~h}$ in length, less the sequences that had missing observation data, as well as the unphysical conditions and spikes and the non-steady sequences that failed the steady-state test. Then, the seasonal sequences were examined in detail, with 1147 (1310) samples of spring vapour (temperature) covariance $\overline{w^{\prime} q^{\prime}}\left(\overline{w^{\prime} T^{\prime}}\right), 1182$ (1319) samples of summer covariance $\overline{w^{\prime} q^{\prime}}\left(\overline{w^{\prime} T^{\prime}}\right), 1257$ (1423) samples of autumnal covariance $\overline{w^{\prime} q^{\prime}}\left(\overline{w^{\prime} T^{\prime}}\right), 1184$ (1403) samples of winter covariance $\overline{w^{\prime} q^{\prime}}\left(\overline{w^{\prime} T^{\prime}}\right)$, all of which meet the conditions for the Ogive analysis.

According to Foken et al. (2006), there are three different cases for the behaviour of the Ogive functions, as shown in Table 3. These three cases were used to investigate the effect of the low frequency flux on the turbulence flux with a 30min average period. The Ogive results are shown in Fig. 10. For the Ogive-analysis temperature covariance $\left(\mathrm{Og}_{w T}\right)$ characterizing the Ogive-treated sensible heat flux, samples satisfying Case 1 prevailed for all the seasons, with more than $75 \%$ of the Ogives showing the convergent curve in spring and summer, compared to about $70 \%(60 \%)$ in autumn (winter). Both Case 2 and 3 were greater than $10 \%$ in all seasons except spring, and Case 2 was slightly greater than Case 3. Further examination shows that the non-convergent Ogive function curve of temperature covariance $\left(\overline{w^{\prime} T^{\prime}}\right)$ occurs typically at night, around midnight and sunrise, when sensible heat fluxes are negative and the mean temperature is low.

According to the Ogive function analysis of the humidity covariance $\mathrm{Og}_{w q}$ characterizing the Ogive-treated latent heat flux, the seasonal portions of the latent heat flux samples satisfying Case 1 are much lower than that of the sensible heat flux in the same season. The portion of samples meeting 
Table 4. Energy balance closure from 5-cm-depth soil heat flux vs surface soil heat flux.

\begin{tabular}{|c|c|c|c|c|c|c|c|c|c|}
\hline & \multicolumn{3}{|c|}{$\left(\mathrm{LE}+H_{\mathrm{s}}\right) /\left(R_{\mathrm{n}}-G_{-5 \mathrm{~cm}}\right)$} & \multicolumn{3}{|c|}{$\left(\mathrm{LE}+H_{\mathrm{s}}\right) /\left(R_{\mathrm{n}}-G_{0, \text { PlateCal }}\right)$} & \multicolumn{3}{|c|}{$\left(\mathrm{LE}+H_{\mathrm{s}}\right) /\left(R_{\mathrm{n}}-G_{0, \mathrm{TDEC}}\right)$} \\
\hline & Slope & Intercept & $R^{2}$ & Slope & Intercept & $R^{2}$ & Slope & Intercept & $R^{2}$ \\
\hline Spring & 0.66 & 25.61 & 0.91 & 0.78 & 17.31 & 0.92 & 0.83 & 11.70 & 0.91 \\
\hline Summer & 0.65 & 21.20 & 0.92 & 0.74 & 11.53 & 0.91 & 0.79 & 4.06 & 0.91 \\
\hline Autumn & 0.62 & 17.19 & 0.91 & 0.72 & 12.26 & 0.90 & 0.76 & 12.40 & 0.90 \\
\hline Winter & 0.55 & 17.05 & 0.90 & 0.63 & 16.13 & 0.87 & 0.61 & 18.72 & 0.85 \\
\hline
\end{tabular}
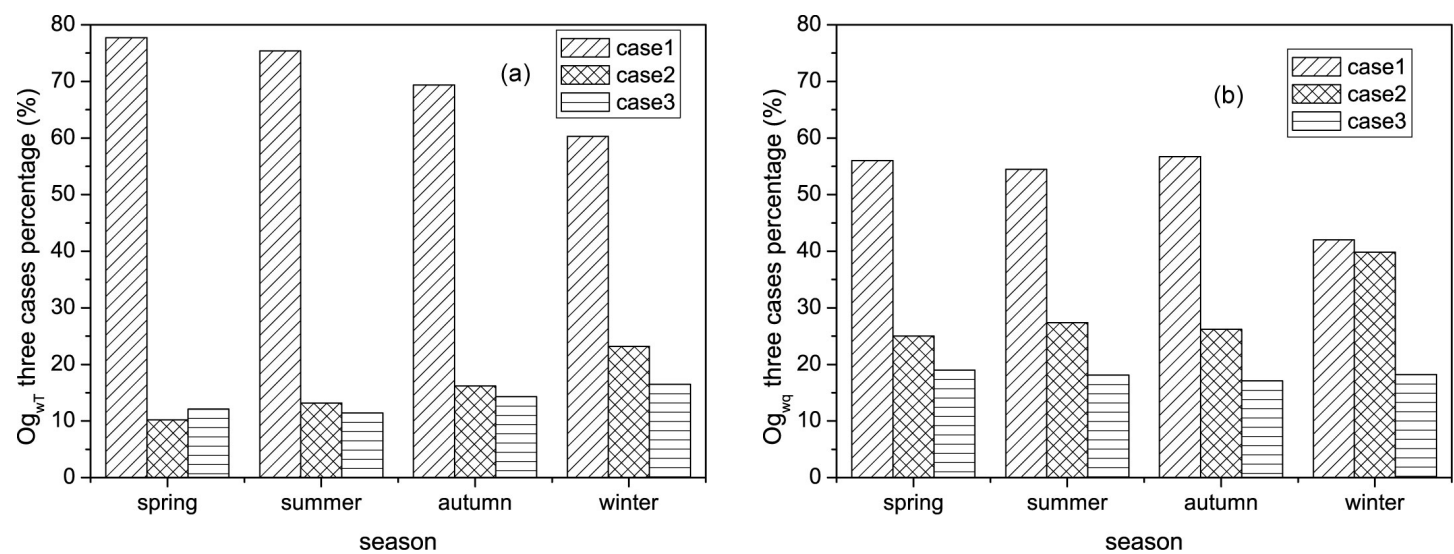

Fig. 10. Seasonal distribution of Ogive function analysis for three cases for (a) sensible $\left(\mathrm{Og}_{w T}\right)$ and (b) $\operatorname{latent}_{(\mathrm{Og}}(\mathrm{g})$ heat flux from $\mathrm{SACOL}$ data at the SACOL site.

Case 1 is about $55 \%$ in all seasons except winter $(42 \%)$, suggesting that the latent heat flux is greatly underestimated, which may make energy balance unclosure larger in winter. Most of the non-convergent portion of the Ogive curve generally takes place during stable night-time conditions, or in the event of a sudden change of the relative humidity, as for example, in the evening and around sunrise. The analysis of $\mathrm{Og}_{w T}$ and $\mathrm{Og}_{w q}$ shows that the sensible and latent heat fluxes are possibly underestimated to different extents under the effect of the low-frequency part of the turbulence spectrum, with the condition of the 30 -min average period. Further, the analysis shows that the effect is the least in the spring and summer, greater in autumn, and maximum in the winter.

To further understand the surface EBC in relation to the low-frequency turbulence spectra itself, the data were then divided into two parts, according to the Ogive function, in order to be analysed. Here, $G_{0}$ was calculated with the PlateCal approach. One part of the data are those Ogives of temperature and humidity covariance which satisfy Case 1; the other part includes the rest of the data. As shown in Fig. 11, the EBC of data satisfying Case 1 show increases of 4, 4, 8, and $7 \%$ compared with the EBC of data except Case 1 respectively for spring, summer, autumn, and winter. The EBC has improved to some extent in the various seasons due to eliminating the effect of low-frequency flux. Because the ratio of the data satisfying Case 1 is much higher than the ratio of those that do not satisfy Case 1, the impact of low-frequency flux is not obvious. Its effect on the EBC is similar in all four seasons, and is stable as well.

\subsection{Effect of turbulence intensity on EBC}

The above factors, which are related to the underlying surface condition and the limitations of observational techniques or methods, prevent the energy balance from being closed. In order to study whether atmospheric turbulence itself will affect the EBC, the following section analyses the relationship between relative turbulence intensity, $\mathrm{RI}_{w}$, and $\mathrm{EBC}$.

The observations are separated into two parts, one for the day and the other for the night. For both the day $\left(R_{\mathrm{n}}>0.0 \mathrm{~W} \mathrm{~m}^{-2}\right)$ and the night $\left(R_{\mathrm{n}} \leq 0.0 \mathrm{~W} \mathrm{~m}^{-2}\right)$, the data are divided into 10 equal sections, each accounting for $10 \%$ of the total data, to explore the relationship between OLS slope and $\mathrm{RI}_{w}$.

Figure 12 depicts the $\mathrm{RI}_{w}$-OLS slope relationship during the day and night in all seasons. In general, the EBC feature is better by day than by night, and the OLS slope enlarges appreciably as a function of increasing $\mathrm{RI}_{w}$. During the day, turbulence can often be fully developed because of the role of global solar radiation, and the relative turbulence is strong. In spring (Fig. 12a) the daytime EBC is good, with an OLS slope of 0.60 at lower $\mathrm{RI}_{w}$, increasing markedly with $\mathrm{RI}_{w}$ to about 0.78 at $\mathrm{RI}_{w}=0.10$, followed by a slower increase with $\mathrm{RI}_{w}$, and arriving at an OLS slope of 0.80 at higher $\mathrm{RI}_{w}$. The 


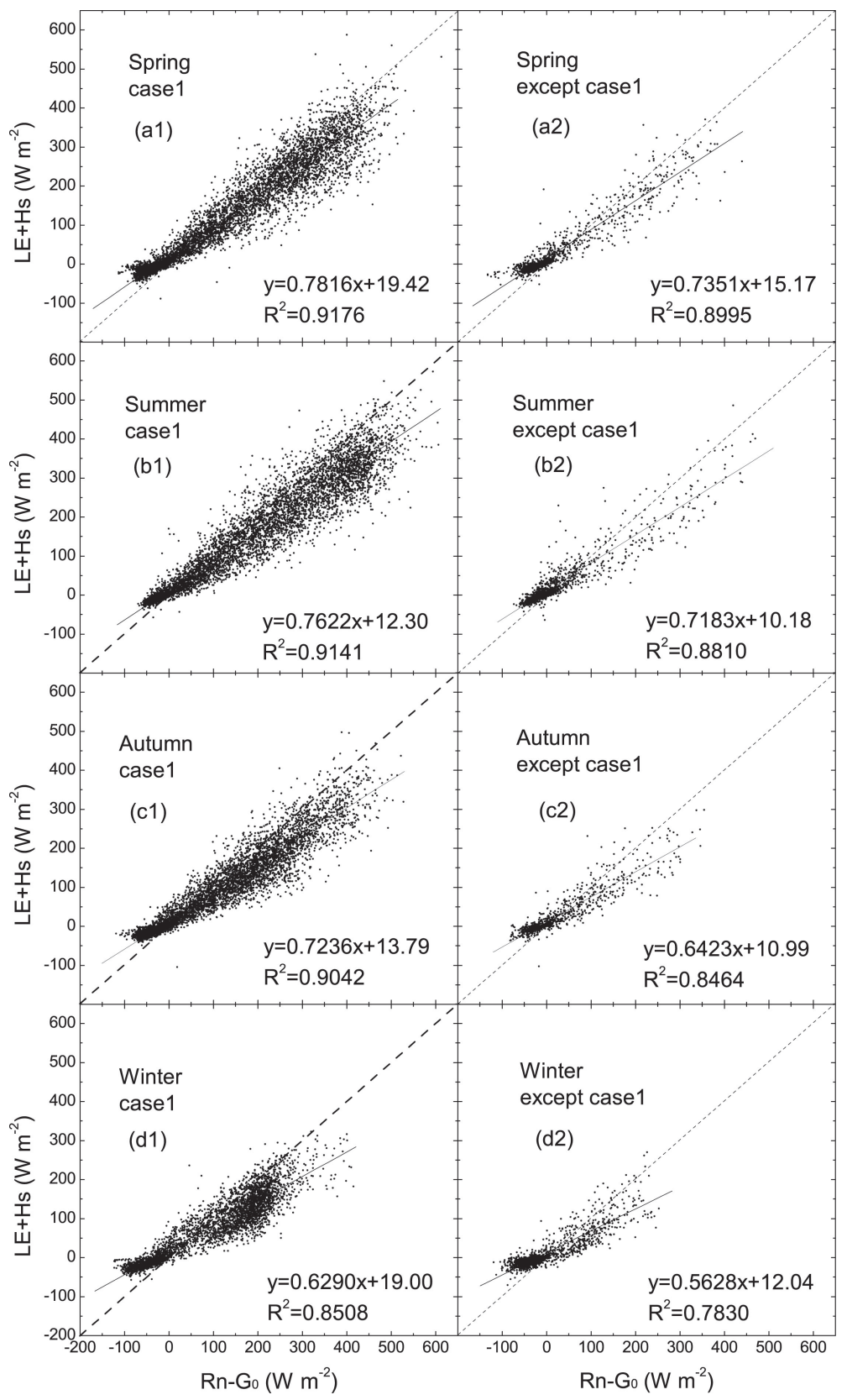

Fig. 11. Seasonal effect of the low-frequency part of the turbulence spectra on EBC at SACOL site. Here, $G_{0}$ is calculated with PlateCal approach. (a1) data of Case 1 for $\mathrm{Og}_{w T}$ and $\mathrm{Og}_{w q}$ in spring; (a2) data without Case 1 for $\mathrm{Og}_{w T}$ and $\mathrm{Og}_{w q}$ in spring; (b1) same as (a1) but in summer; (b2) same as (a2) but in summer; (c1) same as (a1) but in autumn; (c2) same as (a2) but in autumn; (d1) same as (a1) but in winter; (d2) same as (a2) but in winter.

summer variations of the OLS slope with $\mathrm{RI}_{w}$ are similar to those in the spring. The OLS slope is about 0.55 at lower $\mathrm{RI}_{w}, 0.76$ at $\mathrm{RI}_{w}=0.15$, and 0.80 at higher $\mathrm{RI}_{w}$ in summer (Fig. 12b). In autumn, the OLS slope is about 0.60 at lower $\mathrm{RI}_{w}, 0.80$ at $\mathrm{RI}_{w}=0.16$, and 0.80 at higher $\mathrm{RI}_{w}$ (Fig. 12c). Finally, in winter, the OLS slope is about 0.50 at lower $\mathrm{RI}_{w}$, 0.70 at $\mathrm{RI}_{w}=0.15$ and 0.65 at higher $\mathrm{RI}_{w}$ (Fig. 12d). The atmosphere is stable at night, thus the relative turbulence intensity is lower at night than during the day. In fact, the relative turbulence intensity at night does not exceed 0.18 . It also can be seen from Fig. 12 that the EBC is different in various seasons, but the OLS slope increases noticeably as a function of $\mathrm{RI}_{w}$. 


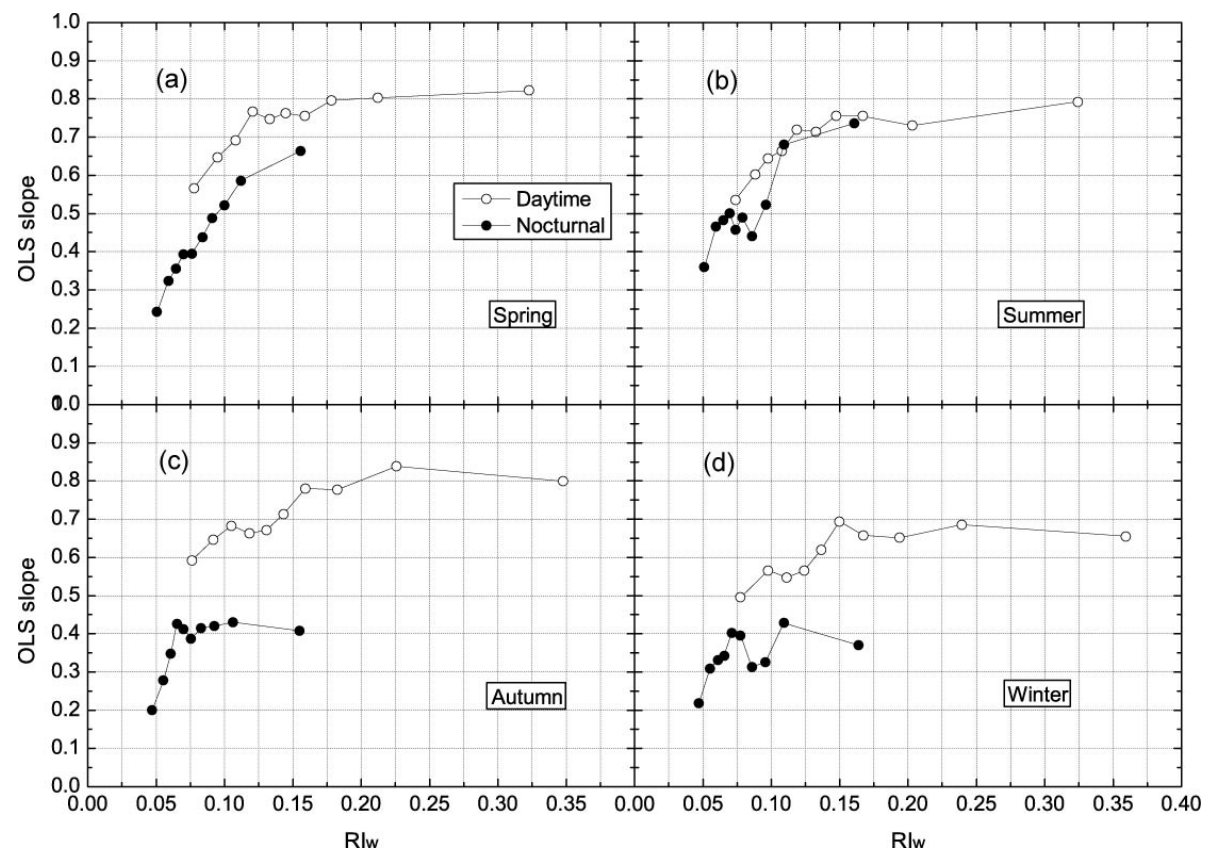

Fig. 12. Seasonal effect of relative turbulence intensity on EBC denoted as OLS slope over the native grassland of the semi-arid Loess Plateau, in (a) spring, (b) summer, (c) autumn, and (d) winter.

Analysis of actual observation data shows that the surface EBC depends on the atmospheric motion state. There is a close relationship between the $\mathrm{EBC}$ and the turbulence intensity. It follows that the poor EBC is derived from the weak turbulence. During the day, EBC can reach a stable condition when the turbulence mixing reaches a certain degree. Moreover, although the relative vertical turbulence intensity is different from season to season over native grassland on the semi-arid Loess Plateau, the changes are consistent between the $\mathrm{EBC}$ and the $\mathrm{RI}_{w}$. The effect of $\mathrm{RI}_{w}$ on the $\mathrm{EBC}$ is similar in all four seasons, and is stable.

\section{Conclusions}

At present, EC has become a standard tool in the study of the terrestrial carbon, water, and energy cycles. The lack of EBC is a serious problem that must be confronted by micrometeorologists. Using data observed in many places and different time scales, some explanations of the lack of EBC are given, but the lack of energy balance is still there. Further experiments are required to identify additional factors causing the energy imbalance.

Based on SACOL eddy-covariance data from 2006 to 2010, an intensive study of the seasonal energy balance was conducted. In this study, the effect various factors on the EBC were examined, including the flux contribution from the target zone, the low-frequency part of the turbulence spectra, surface soil heat flux calculations, and the strength of atmospheric turbulence motion.
Although the lack of energy balance is clearly evident, the variation in the trend reasonably represents the interaction between the atmosphere and the land in the semi-arid Loess Plateau. $H_{\mathrm{s}}$ is distinctly larger than LE in spring and winter, with the energy transport dominated by sensible heat flux in the near-surface layer. It was also found that sensible heat flux is nearly equivalent to latent heat flux in summer and autumn.

Recent studies on EBC have found that the methods to calculate surface soil heat flux, the flux contribution from the target area, and the loss of the low-frequency part of the turbulence spectra have a great impact on the energy closure. The inclusion of the soil heat storage terms in the energy budget yields a great improvement in the total closure, especially for the daytime; but the calculated soil heat flux cannot explain the all gap in EBC, so a more accurate scheme of SSHF will improve the EBC study in an effective manner. As the flux contribution grows, the OLS slope increases correspondingly, but even when the contribution reaches $100 \%$, the energy balance fails to be completely closed. It was found that the flux contribution percentage is higher in the subprevailing NW rather than the predominant SE wind. Ogive analysis succeeds in assessing the EBC effect of the lowfrequency turbulent flux, indicating that the relatively smaller impact occurs in spring and summer, with the maximal effect in winter. Moreover, it was found that the portion of underestimated latent heat fluxes is much larger than that of the underestimated sensible heat flux. It should also be mentioned that the term of the canopy storage heat flux could be ignored over the semi-arid Loess Plateau of Northwest China. 
The three factors above are based on the limitations of observation technologies and flux calculation methods. The impact of the strength of atmospheric turbulence on EBC was investigated using the definition of the relative vertical turbulence intensity. The analysis shows that there is a very close relationship between EBC and turbulence intensity. The poor EBC always occurs with lower turbulence intensity. The effect of $\mathrm{RI}_{w}$ on the EBC is similar in all four seasons, and is stable.

Finally, all factors that have a clear impact on energy closure were found to have similar seasonal variation, and, in fact, were also found to be stable. Thus, in conclusion, we have found that surface observations can reveal the characteristics of surface-atmosphere interaction, even though the energy balance residual amounts to a significant $10-30 \%$ of the available energy.

Acknowledgements. This work is supported by the National Natural Science Foundation of China (Grant No. 40775017) and National Basic Research Program of China (973 Program) (Grant No. 2012CB956200).

Edited by: N. Romano

\section{References}

Baldocchi, D., Falge, E., Gu, L., Olson, R., Hollinger, D., Running, S., Anthoni, P., Bernhofer, C., Davis, K., and Evans, R.: FLUXNET: A New Tool to Study the Temporal and Spatial Variability of Ecosystem-Scale Carbon Dioxide, Water Vapor, and Energy Flux Densities, B. Am. Meteorol. Soc., 82, 2415-2434, 2001.

Betts, A. K., Ball, J. H., Beljaars, A. C. M., Miller, M. J., and Viterbo, P. A.: The land surface-atmosphere interaction: A review based on observational and global modeling perspectives, J. Geophys. Res., 101, 7209-7225, 1996.

Canadell, J. G., Mooney, H. A., Baldocehi, D. D., Berry, J. A., Ehleringer, J. R., Field, C. B., Gower, S. T., Hollinger, D. Y., Hunt, J. E., Jackson, R. B., Runing, S. W., Shaver, G. R., Steffen, W., Trumbore, S. E., Valentini, R., and Bond, B. Y.: Carbon metabolism of the terrestrial biosphere: A multitechnique approach for improved understanding, Ecosystems, 3, 115-130, 2000.

Cava, D., Contini, D., Donateo, A., and Martano, P.: Analysis of short-term closure of the surface energy balance above short vegetation, Agr. Forest Meteorol., 148, 82-93, 2008.

Finnigan, J. J., Clement, R., Malhi, Y., Leuning, R., and Cleugh, H. A.: A re-evaluation of long term flux measurement techniques, Part I: averaging and coordinate rotation, Bound.-Lay. Meteorol., 107, 1-48, 2003.

Foken, T.: The energy balance closure problem: an overview, Ecol. Appl., 18, 1351-1367, 2008.

Foken, T. and Oncley, S. P.: Results of the workshop "Instrumental and methodical problems of land surface flux measurements", B. Am. Meteorol. Soc., 76, 1191-1193, 1995.

Foken, T. and Wichura, B.: Tools for quality assessment of surfacebased flux measurements, Agr. Forest Meteorol., 78, 83-105, 1996.
Foken, T., Göckede, M., Mauder, M., Mahrt, L., Amiro, B., and Munger, W.: Post-field data quality control, in: Handbook of Micrometeorology: A Guide for Surface Flux Measurements, edited by: Lee, X., Massman, W., and Law, B. E., Kluwer, Dordrecht, 181-208, 2004.

Foken, T., Wimmer, F., Mauder, M., Thomas, C., and Liebethal, C.: Some aspects of the energy balance closure problem, Atmos. Chem. Phys., 6, 4395-4402, doi:10.5194/acp-6-4395-2006, 2006.

Fuchs, M.: Heat flux, in: Methods of Soil Analysis, Part 1: Physical and Mineralogical Methods, edited by: Klute, A., Agronomy Monographs, ASA and SSSA, Madison, WI, 957-968, 1986.

Göckede, M., Rebmann, C., and Foken, T.: A combination of quality assessment tools for eddy covariance measurements with footprint modeling for the characterization of complex sites, Agr. Forest Meteorol., 127, 175-188, 2004.

Göckede, M., Foken, T., Aubinet, M., Aurela, M., Banza, J., Bernhofer, C., Bonnefond, J. M., Brunet, Y., Carrara, A., Clement, R., Dellwik, E., Elbers, J., Eugster, W., Fuhrer, J., Granier, A., Grünwald, T., Heinesch, B., Janssens, I. A., Knohl, A., Koeble, R., Laurila, T., Longdoz, B., Manca, G., Marek, M., Markkanen, T., Mateus, J., Matteucci, G., Mauder, M., Migliavacca, M., Minerbi, S., Moncrieff, J., Montagnani, L., Moors, E., Ourcival, J.-M., Papale, D., Pereira, J., Pilegaard, K., Pita, G., Rambal, S., Rebmann, C., Rodrigues, A., Rotenberg, E., Sanz, M. J., Sedlak, P., Seufert, G., Siebicke, L., Soussana, J. F., Valentini, R., Vesala, T., Verbeeck, H., and Yakir, D.: Quality control of CarboEurope flux data - Part 1: Coupling footprint analyses with flux data quality assessment to evaluate sites in forest ecosystems, Biogeosciences, 5, 433-450, doi:10.5194/bg-5-433-2008, 2008.

Hendricks Franssen, H. J., Stöckli, R., Lehner, I., Rotenberg, E., and Seneviratne, S. I.: Energy balance closure of eddy-covariance data: A multisite analysis for European FLUXNET stations, Agr. Forest Meteorol., 150, 1553-1567, 2010.

Heusinkveld, B. G., Jacobs, A. F. G., Holtslag, A. A. M., and Berkowicz, S. M.: Surface energy balance closure in an arid region: role of soil heat flux, Agr. Forest Meteorol., 122, 21-37, 2004.

Huang, J. P., Zhang, W., Zuo, J. Q., Bi, J. R., Shi, J. S., Wang, X., Chang, Z. L., Huang, Z. W., Yang, S., Zhang, B. D., Wang, G. Y., Feng, G. H., Yuan, J. Y., Zhang, L., Zuo, H. C., Wang, S. G., Fu, C. B., and Chou, J. F.: An overview of the semi-arid climate and environment research observatory over the Loess Plateau, Adv. Atmos. Sci., 25, 906-921, 2008.

Kormann, R. and Meixner, F. X.: An analytical footprint model for non-neutral stratification, Bound.-Lay. Meteorol., 99, 207-224, 2001.

Kukharets, V. P., Nalbandyan, H. G., and Foken, T.: Thermal Interactions between the underlying surface and a nonstationary radiation flux, Izv., Atmos. Ocean. Phys., 36, 318-325, 2000.

Li, Z. Q., Yu, G. R., Wen, X. F., Zhang, L. M., and Ren, C. Y.: Energy balance closure at China FLUX sites, Sci. China Ser. D, 48, Supp. I, 51-62, 2005.

Liebethal, C., Huwe, B., and Foken, T.: Sensitivity analysis for two ground heat flux calculation approaches, Agr. Forest Meteorol., 132, 253-262, 2005.

Liu, H., Peters, G., and Foken, T.: New equations for sonic temperature variance and buoyancy heat flux with an omnidirectional 
sonic anemometer, Bound.-Lay. Meteorol., 100, 459-468, 2001.

McCaughey, J. H.: Energy balance storage terms in a mature mixed forest at Petawawa, Ontario - A case study, Bound.-Lay. Meteorol., 31, 89-101, 1985.

Merry, M. and Panofsky, H. A.: Statistics of vertical motion over land and water, Q. J. Roy. Meteorol. Soc., 102, 255-260, 1976.

Moncrieff, J., Clement, R., Finnigan, J., and Meyers, T.: Averaging, detrending, and filtering of eddy covariance time series, in: Handbook of Micrometeorology, Kluwer Acad. Dordrecht, New York, Boston, Dordrecht, London, Moscow, 7-31, 2005.

Moore, C. J.: Frequency response corrections for eddy correlation systems, Bound.-Lay. Meteorol., 37, 17-35, 1986.

Oliphant, A. J., Grimmond, C. S. B., Zutter, H. N., Schmid, H. P., Su, H.-B., Scott, S. L., Offerle, B., Randolph, J. C., and Ehman, J.: Heat storage and energy balance fluxes for a temperate deciduous forest, Agr. Forest Meteorol., 126, 185-201, 2004.

Oncley, S. P., Foken, T., Vogt, R., Kohsiek, W., Debruin, H. A. R., Bernhofer, C., Christen, A., Gorsel, E. V., Grantz, D., Feigenwinter, C., Lehner, I., Liebethal, C., Liu, H., Mauder, M., Pitacco, A., Ribeiro, L., and Weidinger, T.: The energy balance experiment EBEX-2000, Part I: overview and energy balance, Bound.-Lay. Meteorol., 123, 1-28, 2007.

Panin, G. N., Tetzlaff, G., and Raabe, A.: Inhomogeneity of the land surface and problems in the parameterization of surface fluxes in natural conditions, Theor. Appl. Climatol., 60, 163-178, 1998.

Pielke, R. A., Avissar, S. R., Raupach, M., Dolman, A. J., Zeng, X., and Denning, A. S.: Interactions between the atmosphere and terrestrial ecosystems: Influence on weather and climate, Glob. Change Biol., 4, 461-475, 1998.

Qian, L. Q. (Ed.): Climate on the Loess Plateau in China, China Meteorology Press, Beijing, 1991 (in Chinese).

Rebmann, C., Göckede, M., Foken, T., Aubinet, M., Aurela, M., Berbigier, P., Bernhofer, C., Buchmann, N., Carrara, A., Cescatti, A., Ceulemans, R., Clement, R., Elbers, J. A., Granier, A., Grünwald, T., Guyon, D., Havránková, K., Heinesch, B., Knohl, A., Laurila, T., Longdoz, B., Marcolla, B., Markkanen, T., Miglietta, F., Moncrieff, J., Montagnani, L., Moors, E., Nardino, M., Ourcival, J.-M., Rambal, S., Rannik, Ü., Rotenberg, E., Sedlak, P., Unterhuber, G., Vesala, T., and Yakir, D.: Quality analysis applied on eddy covariance measurements at complex forest sites using footprint modelling, Theor. Appl. Climatol., 80, 121-141, 2005.
Running, S. W., Baldocchi, D. D., Turner, D. P., Gower, S. T., Bakwin, P. S., and Hibbard, K. A.: A global terrestrial monitoring network, integrating tower fluxes, flask sampling, ecosystem modeling and EOS satellite data, Remote Sens. Environ., 70, 108-127, 1999.

Sánchez, J. M., Caselles, V., and Rubio, E. M.: Analysis of the energy balance closure over a FLUXNET boreal forest in Finland, Hydrol. Earth Syst. Sci., 14, 1487-1497, doi:10.5194/hess-141487-2010, 2010.

Schotanus, P., Nieuwstadt, F. T. M., and DeBruin, H. A. R.: Temperature measurement with a sonic anemometer and its application to heat and moisture fluxes, Bound.-Lay. Meteorol., 26, 81-93, 1983.

Sellers, P. J., Randall, D. A., Collatz, G. J., Berry, J. A., Field, C. B., Dazlich, D. A., Zhang, C., Collelo, G. D., and Bounoua, L.: A revised land surface parameterization $(\mathrm{SiB} 2)$ for atmospheric GCMs, Part 1: Model formulation, J. Climate, 9, 676-705, 1996.

Vickers, D. and Mahrt, L.: Quality control and flux sampling problems for tower and aircraft data, J. Atmos. Ocean. Tech., 14, 512526, 1997.

Webb, E. K., Pearman, G. I., and Leuning, R.: Correction of flux measurements for density effects due to heat and water vapour transfer, Q. J. Roy. Meteor. Soc., 106, 85-100, 1980.

Wilczak, J. M., Oncley, S. P., and Stage, S. A.: Sonic anemometer tilt correction algorithms, Bound.-Lay. Meteorol., 99, 127-150, 2001.

Wilson, K., Goldstein, A., Falge, E., Aubinet, M., Baldocchi, D., Berbigier, P., Bernhofer, C., Ceulemans, R., Dolman, H., Field, C., Grelle, A., Ibrom, A., Law, B. E., Kowalski, A., Meyers, T., Moncrieff, J., Monson, R., Oechel, W., Tenhunen, J., Valentini, R., and Verma, S.: Energy balance closure at FLUXNET sites, Agr. Forest Meteorol., 113, 223-243, 2002.

Yang, K. and Wang, J. M.: A temperature prediction-correction method for estimating surface soil heat flux from soil temperature and moisture data, Sci. China Ser. D, 5, 721-729, 2008. 